OPEN ACCESS

Edited by:

Rosa M. Rivero,

Centro de Edafología y Biología Aplicada del Segura (CSIC), Spain

Reviewed by: Nobuhiro Suzuki,

Sophia University, Japan Juan Jose Rios,

Centro de Edafología y Biología Aplicada del Segura (CSIC), Spain

*Correspondence:

Qianyu Jin

jinqy@mail.hz.zj.cn

tThese authors have contributed equally to this work.

Specialty section: This article was submitted to

Plant Abiotic Stress,

a section of the journal

Frontiers in Plant Science

Received: 03 March 2017 Accepted: 06 June 2017 Published: 23 June 2017

Citation:

Zhong C, Cao X, Hu J, Zhu L, Zhang J, Huang J and Jin Q (2017) Nitrogen Metabolism in Adaptation of Photosynthesis to Water Stress in Rice Grown under Different Nitrogen Levels.

Front. Plant Sci. 8:1079. doi: 10.3389/fpls.2017.01079

\section{Nitrogen Metabolism in Adaptation of Photosynthesis to Water Stress in Rice Grown under Different Nitrogen Levels}

\author{
Chu Zhong ${ }^{1,2 t}$, Xiaochuang Cao ${ }^{1 t}$, Jijie Hu ${ }^{1}$, Lianfeng Zhu' ${ }^{1}$, Junhua Zhang', \\ Jianliang Huang ${ }^{2}$ and Qianyu Jin ${ }^{1 *}$
}

${ }^{1}$ National Key Laboratory of Rice Biology, China National Rice Research Institute, Hangzhou, China, ${ }^{2}$ Crop Physiology and

Production Center, Huazhong Agricultural University, Wuhan, China

To investigate the role of nitrogen $(\mathrm{N})$ metabolism in the adaptation of photosynthesis to water stress in rice, a hydroponic experiment supplying with low $\mathrm{N}(0.72 \mathrm{mM})$, moderate $\mathrm{N}(2.86 \mathrm{mM})$, and high $\mathrm{N}(7.15 \mathrm{mM})$ followed by $150 \mathrm{~g} \cdot \mathrm{L}^{-1}$ PEG-6000 induced water stress was conducted in a rainout shelter. Water stress induced stomatal limitation to photosynthesis at low $\mathrm{N}$, but no significant effect was observed at moderate and high N. Non-photochemical quenching was higher at moderate and high N. In contrast, relative excessive energy at PSII level (EXC) was declined with increasing $\mathrm{N}$ level. Malondialdehyde and hydrogen peroxide $\left(\mathrm{H}_{2} \mathrm{O}_{2}\right)$ contents were in parallel with EXC. Water stress decreased catalase and ascorbate peroxidase activities at low $\mathrm{N}$, resulting in increased $\mathrm{H}_{2} \mathrm{O}_{2}$ content and severer membrane lipid peroxidation; whereas the activities of antioxidative enzymes were increased at high N. In accordance with photosynthetic rate and antioxidative enzymes, water stress decreased the activities of key enzymes involving in $\mathrm{N}$ metabolism such as glutamate synthase and glutamate dehydrogenase, and photorespiratory key enzyme glycolate oxidase at low N. Concurrently, water stress increased nitrate content significantly at low N, but decreased nitrate content at moderate and high N. Contrary to nitrate, water stress increased proline content at moderate and high $\mathrm{N}$. Our results suggest that $\mathrm{N}$ metabolism appears to be associated with the tolerance of photosynthesis to water stress in rice via affecting $\mathrm{CO}_{2}$ diffusion, antioxidant capacity, and osmotic adjustment.

Keywords: water deficit, nitrogen level, photosynthesis, nitrogen assimilation, rice (Oryza sativa L.)

\section{INTRODUCTION}

Nitrogen $(\mathrm{N})$ fertilizer plays a vital role in yield increasing of major food crops worldwide during the second half of the 20th century (Chardon et al., 2012; Lassaletta et al., 2014). As diminishing returns of increasing investment of $\mathrm{N}$ fertilizer, excessive application of $\mathrm{N}$ fertilizer causes stagnation of crop yield and lowers nitrogen use efficiency (NUE) of crops (Lawlor, 2002). Photosynthesis is recognized as one of the most efficient ways to increase NUE and crop yield (Kumar et al., 2006). Zhu et al. (2010) have proposed that further increases in crop yield potential will rely in large part on improved photosynthesis. However, improvement of photosynthesis in field conditions confronts some challenges, and the most influential one is seasonal and regional 
water stress. The exposure of plants to water-limiting conditions results in the decreases in gas exchange and chlorophyll fluorescence triggered by increased resistance to $\mathrm{CO}_{2}$ diffusion and metabolic constraints (Chaves and Oliveira, 2004; Pinheiro and Chaves, 2011). To better understand the underlying physiological mechanisms that plant photosynthesis in response to reduced water availability and how these can be manipulated are essential to improve plant photosynthetic capacity.

The majority of assimilated $\mathrm{N}$ in plant is invested in photosynthetic machinery (Nunes-Nesi et al., 2010). Therefore, $\mathrm{N}$ is fairly strong positive correlated with photosynthetic rate (Makino et al., 2000, 2003). In addition to directly taking part in photosynthesis, $\mathrm{N}$ acts as an important regulator in manipulation of $\mathrm{CO}_{2}$ diffusion as indicated by the strong positive correlation between $\mathrm{N}$ and stomatal conductance $\left(g_{\mathrm{s}}\right)$ or mesophyll conductance $\left(g_{\mathrm{m}}\right)$ (Tosens et al., 2012; Xiong et al., 2015). In fact, nitrogenous compounds in and outside plant play an essential role as signals in regulating the responses of plants to environmental changes (Tabuchi et al., 2007; Gojon et al., 2009). It has been well documented that nitrate uptake, allocation, and assimilation in plants were closely associated with the resistance of plants to adverse conditions including water stress (Chen et al., 2012; Atkinson et al., 2014; Fang et al., 2016).

The regulatory function of $\mathrm{N}$ in water stress tolerance of plant depends upon the intensity of stress and $\mathrm{N}$ level. Proper $\mathrm{N}$ level supports regular plant growth and helps plants to defense stress (Chang et al., 2016). It has been proposed that crops supplied with relative higher $\mathrm{N}$ had better growth performance than that supplied with low $\mathrm{N}$ under drought stress (Haefele et al., 2008; Tran and Yamauchi, 2014; Wang et al., 2016). Higher N mitigates the adverse effects of water stress on photosynthesis as well. Otoo et al. (1989) revealed that relative to low $\mathrm{N}$, higher $\mathrm{N}$ increased the sensitivity of $g_{s}$ to water stress and maintained better photosynthetic machinery in rice. Increased resistance of photosynthesis to water stress at higher $\mathrm{N}$ also resulted from improved enzymatic and/or non-enzymatic antioxidant systems (Chang et al., 2016). Besides, more $\mathrm{N}$ is allocated to soluble organic nitrogenous compounds, such as proline and other amino acids under higher $\mathrm{N}$ levels, which act as osmotica to balance water status in plant cell under osmotic stress (Funk et al., 2013; Singh et al., 2016).

Nitrogen metabolism regulation is crucial for stress tolerance and involves almost all physiological processes in plants (Lawlor, 2002). Water stress induced reduction in photosynthesis was associated with the decline in N metabolism (Garg et al., 2001; Xu and Zhou, 2005, 2006). Glutamine synthase (GS) and glutamate synthase (GOGAT) are the key enzymes for incorporation of inorganic $\mathrm{N}$ into amides and amino acids in cell, bridging carbon and nitrogen metabolism. Singh et al. (2015) demonstrated that soil drying reduced the activities of these enzymes as well as $\mathrm{N}$ uptake and contents of nitrogenous compounds in leaves of sunflower seedlings. Ammonium is a central intermediate product of nitrogen metabolism in plants. It derives from external source by root uptake and reduction of nitrate, or from internal source by degradation of amino acids and photorespiration (Thomsen et al., 2014). As high concentration of ammonium is toxic to plant cell, the high capacity to assimilate ammonium could be an important factor in alleviating the consequence of stress (Hoai et al., 2003). GS involves in the process of ammonium assimilation and reassimilation (Miflin and Habash, 2002). It has been recognized as a metabolic indicator of drought stress tolerance in wheat (Nagy et al., 2013). The cytosolic (GS1) and chloroplastic (GS2) isoforms of GS catalyze the assimilation of ammonium derived from different sources (Miflin and Habash, 2002; Thomsen et al., 2014). It has been reported that the activities of GS1 and GS2 isozymes varied substantially in different water-sensitive cultivars of rice when exposed to water stress (Singh and Ghosh, 2013). This suggests that the different tolerance of rice cultivar to water stress may partly attribute to ammonium assimilation and/or reassimilation (Hoai et al., 2003). However, further research is needed on how $\mathrm{N}$ metabolism contributes to water stress tolerance in rice.

Rice (Oryza sativa L.) is a water intensive crop. For example, in Asia, where rice cultivation area accounts for over $90 \%$ of the world, rice cultivation consumes up to $80 \%$ of agricultural irrigation water (Bouman and Tuong, 2001). Developing water-saving irrigation in rice production is of great significance to sustainable development of agriculture. Water-saving irrigation, e.g., alternate wetting and drying (AWD), alters the relationship between water and nitrogen status in the field, which may affect fundamental biochemical processes and eventually grain yield in rice plants (Dodd et al., 2015; Wang et al., 2016). The aim of this study was to examine the role of $\mathrm{N}$ metabolism in the adaptation of photosynthesis to water stress in rice.

\section{MATERIALS AND METHODS}

\section{Plant Material and Growth Condition}

Seeds of hybrid indica rice cultivar 'Zhongzheyou 1' were germinated and grown hydroponically in a nutrient medium described as follows. At third leaf stage, the seedlings were started to be supplied with $1 / 2$ strength nutrient solution. At sixth leaf stage, the seedlings were transplanted to 5 -L pots with sponge wrapped around the interface of the root and the shoot and cultivated with nutrient medium. The full-strength nutrient medium contained $1.43 \mathrm{mM} \mathrm{NH}_{4} \mathrm{NO}_{3}(2.86 \mathrm{mM} \mathrm{N}), 0.32 \mathrm{mM}$ $\mathrm{NaH}_{2} \mathrm{PO}_{4}, 0.5 \mathrm{mM} \mathrm{K}_{2} \mathrm{SO}_{4}, 1.0 \mathrm{mM} \mathrm{CaCl}, 1.7 \mathrm{mM} \mathrm{MgSO}$, $9.1 \mathrm{mM} \mathrm{MnCl} 2,0.52 \mu \mathrm{M}\left(\mathrm{NH}_{4}\right)_{6} \mathrm{Mo}_{7} \mathrm{O}_{24}, 18.0 \mu \mathrm{M} \mathrm{H}_{3} \mathrm{BO}_{3}$, $0.15 \mu \mathrm{M} \mathrm{ZnSO}_{4}, 0.16 \mu \mathrm{M} \mathrm{CuSO}_{4}, 36.0 \mu \mathrm{M} \mathrm{FeCl}_{3}$, and $70 \mu \mathrm{M}$ citric acid. Additional $50 \mathrm{~mL}$ concentrated sulfuric acid and $10 \mathrm{~g}$ EDTA-Na $\mathrm{Na}_{2}$ were added in per liter of micronutrient mixture solution.

At the first 4 days after transplanting, seedlings were supplied with $1 / 2$-strength nutrient solution (1.43 $\mathrm{mM} \mathrm{N})$, and then followed by supplied with full-strength nutrient solution (2.86 mM N) during the next 10 days. After $\mathrm{N}$ starvation for 1 day, seedlings were separated into three groups, and provided with $0.72 \mathrm{mM} \mathrm{N}$ (low N), $2.86 \mathrm{mM} \mathrm{N}$ (moderate N), and $7.15 \mathrm{mM} \mathrm{N}$ (high $\mathrm{N}$ ), respectively, for additional 10 days until the occurrence of significant phenotypic difference in plant size and leaf color. In the following 5 days of $\mathrm{N}$ treatment, half of the plants in each treatment were treated with $150 \mathrm{~g} \cdot \mathrm{L}^{-1} \mathrm{PEG}(6000)$ as water deficit 
(WD), and with no PEG (6000) as control (well-watered, WW). The solution was refreshed twice a week to maintain a $\mathrm{pH}$ of $5.50 \pm 0.05$.

The experiment had six treatments (three $\mathrm{N}$ levels and two water conditions), and each treatment had four independent pots, each of which consisted of four independent plants. The experiment was arranged in a completely randomized design in a factorial $(3 \times 2)$. The position of pots was interchanged when refreshing the solution to eliminate the edge effects.

\section{Gas Exchange and Chlorophyll Fluorescence Measurements}

At the end of water stress episode, photosynthetic measurement was conducted on the youngest fully expanded leaves (second from top). In order to ensure that all measurements were conducted under identical conditions, the plants were transferred to a climatic chamber prior to the measurement to acclimate for 1 day in a 12 -h photoperiod regime. The climatic chamber was maintained at $30 / 25^{\circ} \mathrm{C}$ day/night temperature regime with $800 \mu \mathrm{mol} \cdot \mathrm{m}^{-2} \cdot \mathrm{s}^{-1}$ of photosynthetic photon flux density (PPFD) at the top of leaf layer. The $\mathrm{CO}_{2}$ concentration in the chamber was about $400 \mu \mathrm{mol} \cdot \mathrm{mol}^{-1}$, and the relative humidity was about $70 \%$.

The gas exchange and chlorophyll fluorescence were measured simultaneously using LI-6400XT portable photosynthesis system (Li-Cor Inc., Lincoln, NE, United States) and an integrated fluorescence chamber (6400-40). The initial fluorescence $\left(F_{\mathrm{o}}\right)$ and maximum fluorescence $\left(F_{\mathrm{m}}\right)$ in dark-adapted state were determined at night. Light-saturated photosynthetic rate was measured from 09:00 to 12:00 with a PPFD of $1500 \mu \mathrm{mol} \cdot \mathrm{m}^{-2} \cdot \mathrm{s}^{-1}$, cuvette temperature of $25^{\circ} \mathrm{C}$, reference $\mathrm{CO}_{2}$ concentration of $400 \mu \mathrm{mol} \cdot \mathrm{mol}^{-1}$, and relative humility of $70-80 \%$. Prior to measurement, leaves were placed in the cuvette to acclimate for $10 \mathrm{~min}$. Data were recorded after equilibration to a steady-state. Gas exchange parameters such as net photosynthetic rate $\left(P_{\mathrm{n}}\right)$, transpiration rate $\left(T_{\mathrm{r}}\right)$, intercellular $\mathrm{CO}_{2}$ concentration $\left(C_{\mathrm{i}}\right)$, and stomatal conductance $\left(g_{\mathrm{s}}\right)$ and fluorescence parameters such as $F_{\mathrm{o}}{ }^{\prime}, F_{\mathrm{m}}{ }^{\prime}$, and $F_{\mathrm{S}}$ were used for analysis. The following parameters were assessed (Silva et al., 2015): the maximum quantum yield of photosystem II (PSII) photochemistry $\left[F_{\mathrm{v}} / F_{\mathrm{m}}=\left(F_{\mathrm{m}}-F_{\mathrm{o}}\right) / F_{\mathrm{m}}\right]$, the effective quantum yield of PSII photochemistry $\left[\Phi_{\mathrm{PSII}}=\Delta F / F_{\mathrm{m}}^{\prime}=\left(F_{\mathrm{m}}^{\prime}-F_{\mathrm{s}}\right) / F_{\mathrm{m}}{ }^{\prime}\right]$, the photochemical quenching coefficient $\left[q P=\left(F_{\mathrm{m}}{ }^{\prime}-F_{\mathrm{s}}\right) /\left(F_{\mathrm{m}}{ }^{\prime}-F_{\mathrm{o}}{ }^{\prime}\right)\right]$, the nonphotochemical quenching coefficient $\left[N P Q=\left(F_{\mathrm{m}}-F_{\mathrm{m}}{ }^{\prime}\right) / F_{\mathrm{m}}{ }^{\prime}\right]$, the apparent electron transport rate at PSII level $\left[E T R=\Phi_{\mathrm{PSII}} \times \mathrm{PPFD} \times 0.5 \times \alpha_{\text {leaf }}\right]$, and relative excessive energy at PSII level $\left[E X C=\left(F_{\mathrm{v}} / F_{\mathrm{m}}{ }^{\prime}\right)-\left(\Delta F / F_{\mathrm{m}}{ }^{\prime}\right) /\left(F_{\mathrm{v}} / F_{\mathrm{m}}\right)\right]$. To evaluate $E T R, 0.5$ was used as the fraction of excitation energy distributed to PSII, and $\alpha_{\text {leaf }}$ was used as the fraction of incoming light absorbed by the leaves. According to Li et al. (2009) and Xiong et al. (2015), the value of $\alpha_{\text {leaf }}$ was assumed to be 0.85 .

For measurement of $A-C_{\mathrm{i}}$ response curve, the leaves were placed in the cuvette at a PPFD of $1500 \mu \mathrm{mol} \cdot \mathrm{m}^{-2} \cdot \mathrm{s}^{-1}$ and $\mathrm{CO}_{2}$ concentration of $400 \mu \mathrm{mol} \cdot \mathrm{mol}^{-1}$ prior to measurement to equilibrate for $30 \mathrm{~min}$. Cuvette temperature and relative humidity during measurement were maintained as mentioned above. Gas exchange parameters were then recorded in a series of 1000 , $800,600,400,300,200,150,100$, and $50 \mu \mathrm{mol} \cdot \mathrm{mol}^{-1}$ reference $\mathrm{CO}_{2}$ concentrations $\left(C_{\mathrm{a}}\right)$ when equilibration to a steady-state. Maximum carboxylation rate of Rubisco $\left(V_{\mathrm{c}, \max }\right)$, maximum electron transport rate $\left(J_{\max }\right)$, triose phosphate utilization $(T P U)$, and mesophyll conductance $\left(g_{\mathrm{m}}\right)$ were calculated as in Sharkey et al. (2007).

After determination of photosynthesis, the measured leaves and similar ones were cut, frozen immediately in liquid nitrogen, and stored at $-70^{\circ} \mathrm{C}$ until use.

\section{Collection of Xylem Sap}

To collect xylem exudation, above-ground parts of plants were cut off from $5 \mathrm{~cm}$ above the intersection between the roots and shoots. A known-weight zip-lock bag containing absorbent cotton was covered on the rice stubble for one night (from 18:00 to 8:00) to capture xylem exudation. Then all the bags were collected and sealed and subsequently stored at $-20^{\circ} \mathrm{C}$. The volume of xylem exudation was calculated as the change of weight of bag divided by the density of xylem exudation, which was assumed to be $1.0 \mathrm{~g} \cdot \mathrm{mL}^{-1}$. The xylem secretion rate was expressed as $\mathrm{mL} \cdot \mathrm{h}^{-1}$.

\section{Determination of Leaf Relative Water Content}

Leaf relative water content (RWC) was estimated as $\mathrm{RWC}(\%)=[(\mathrm{Fw}-\mathrm{Dw}) /(\mathrm{Sw}-\mathrm{Dw})] \times 100$. Water-saturated weight $(\mathrm{Sw})$ of $0.4 \mathrm{~g}$ fresh weight $(\mathrm{Fw})$ leaf samples was obtained by keeping leaf disks in distilled water for $6 \mathrm{~h}$. Then the samples were oven-dried at $70^{\circ} \mathrm{C}$ to get a constant dry weight (Dw).

\section{Determination of Chlorophyll Content, Free Amino Acid Content, Proline, and Hydrogen Peroxide Content}

Chlorophyll was extracted with about $0.2 \mathrm{~g}$ fresh leaf disks by $25 \mathrm{~mL}$ mixture of alcohol and acetone (v: $\mathrm{v}=1: 1)$ for $24 \mathrm{~h}$ in the dark at room temperature. The absorbance of the extract was measured at 663, 645, and $470 \mathrm{~nm}$ using a UV-VIS spectrophotometer (UV-2600, Shimadzu, Japan) to estimate chlorophyll $a$, chlorophyll $b$ and carotenoids contents according to the method described in Wellburn and Lichtenthaler (1984).

Total free amino acid content was measured chromometrically using ninhydrin method as in Yokoyama and Hiramatsu (2003) and Sun et al. (2006) with some modifications. Amino acids were extracted with acetic acid/sodium acetate buffer ( $\mathrm{pH} 5.4$ ), and the content of amino acid was photometric determined at $580 \mathrm{~nm}$. Leucine (Leu) was used as standard. Proline content was determined according to the method in Bates et al. (1973), and L-proline was used as standard.

Hydrogen peroxide $\left(\mathrm{H}_{2} \mathrm{O}_{2}\right)$ content was measured as in Brennan and Frenkel (1977) and Yang et al. (2007). Samples of frozen leaves $(0.3 \mathrm{~g})$ were powdered in liquid $\mathrm{N}_{2}$ and homogenized with $5 \mathrm{~mL}$ pre-cooled $10 \mathrm{mM}$ 3-amino-1,2,4-triazole. After centrifuging at $8000 \mathrm{rpm}$ for $10 \mathrm{~min}$ at $4^{\circ} \mathrm{C}$ (Centrifuge $5810 \mathrm{R}$, Eppendorf AG, Germany), 
$2 \mathrm{~mL}$ supernatant and $1 \mathrm{~mL} 0.1 \%$ titanium sulfate in $20 \%$ sulfuric acid were added in $10 \mathrm{~mL}$-centrifuge tube. Placed for $10 \mathrm{~min}$, the samples were centrifuged again at $8000 \mathrm{rpm}$ for $10 \mathrm{~min}$. The supernatant was measured colorimetrically at $410 \mathrm{~nm}$. Standard curve was obtained using $30 \% \mathrm{H}_{2} \mathrm{O}_{2}$ as standard.

\section{Soluble Protein, Lipid Peroxidation, and Antioxidase and Glycolate Oxidase Activities}

Samples of frozen leaves $(0.3 \mathrm{~g})$ were powdered in liquid $\mathrm{N}_{2}$ and homogenized with $6 \mathrm{~mL}$ sodium phosphate buffer ( $\mathrm{pH} 7.8)$. The homogenate was centrifuged at $8000 \mathrm{rpm}$ for $10 \mathrm{~min}$ at $4^{\circ} \mathrm{C}$, then stored at $-70^{\circ} \mathrm{C}$ for the determination of soluble protein and thiobarbituric acid reactive substances (TBARS) contents, and activities of antioxidase and glycolate oxidase (GO). Soluble protein and TBARS were measured according to methods described in Sedmak and Grossberg (1977) and Hodges et al. (1999), respectively. Bovine serum albumin was used as standard in protein assay. TBARS was measured at 600, 532, and $450 \mathrm{~nm}$ and calculated using the molar extinction coefficient of $0.155 \mathrm{mM}^{-1} \cdot \mathrm{cm}^{-1}$. The result was expressed with the unit of nmol TBARS. ${ }^{-1}$ Fw.

Superoxide dismutase (SOD) activity was assayed according to the method described in Giannopolitis and Ries (1977). The SOD reaction system contained $25 \mathrm{mmol}$ sodium phosphate buffer (pH7.8), $13 \mathrm{mmol}$ methionine, $2 \mu \mathrm{mol}$ riboflavin, $10 \mu \mathrm{mol}$ EDTA-Na $2,75 \mu \mathrm{mol}$ nitro blue tetrazolium (NBT), and modest amount extract. Samples were put under light $(300 \mu \mathrm{mol}$ $\mathrm{m}^{-2} \mathrm{~s}^{-1}$ ) for $20 \mathrm{~min}$ and the absorbance was measured chromometrically at $560 \mathrm{~nm}$.

Ascorbate peroxidase (APX) activity was assayed according to Chen and Asada (1989) with some modifications. The reaction system $(3 \mathrm{~mL})$ contained $50 \mathrm{mmol}$ sodium phosphate buffer (pH7.0), $0.3 \mathrm{mmol}$ EDTA-Na $\mathrm{N}_{2}$, and $0.3 \mathrm{mmol}$ ascorbate acid. The reaction was started by adding $0.06 \mathrm{mmol} \mathrm{H}_{2} \mathrm{O}_{2}$, and the absorbance at $290 \mathrm{~nm}$ was monitored for $300 \mathrm{~s}$. APX activity was estimated according to the molar extinct coefficient of ascorbate $\left(2.8 \mathrm{mM}^{-1} \cdot \mathrm{cm}^{-1}\right)$ and expressed as $\mathrm{nmol} \mathrm{ASA} \cdot \mathrm{mg}^{-1}$ Pro $\cdot \mathrm{min}^{-1}$.

Catalase (CAT) activity was determined after the reaction of the extract in the presence of $50 \mathrm{mmol}$ sodium phosphate buffer (pH7.0) and $20 \mathrm{mmol} \mathrm{H}_{2} \mathrm{O}_{2}(3 \mathrm{~mL})$. The reaction was carried out at $30^{\circ} \mathrm{C}$, and the absorbance at $240 \mathrm{~nm}$ was monitored for $300 \mathrm{~s}$ (Havir and Mchale, 1987). CAT activity was calculated according to the molar extinct coefficient of $\mathrm{H}_{2} \mathrm{O}_{2}\left(36 \mathrm{mM}^{-1} \cdot \mathrm{cm}^{-1}\right)$ and expressed as nmol $\mathrm{H}_{2} \mathrm{O}_{2} \cdot \mathrm{mg}^{-1}$ Pro $\cdot \mathrm{min}^{-1}$.

Glycolate oxidase activity was measured by the formation of glyoxylate-phenylhydrazone complex at $324 \mathrm{~nm}$ (Baker and Tolbert, 1966). The GO assay mixture (2 mL) contained $50 \mathrm{mmol}$ sodium phosphate buffer (pH7.0, containing $0.1 \mathrm{mmol}$ flavin mononucleotide), $10 \mathrm{mmol}$ phenylhydrazine, $100 \mathrm{mmol}$ L-cysteine, and $0.1 \mathrm{~mL}$ extract. The reaction was carried out at $30^{\circ} \mathrm{C}$ and started with the addition of $100 \mathrm{mmol}$ glycolic acid. The absorbance was monitored for $300 \mathrm{~s}$. The GO activity was calculated using the molar extinction coefficient of the glyoxylatephenylhydrazone complex $\left(17 \mathrm{mM}^{-1} \mathrm{~cm}^{-1}\right)$ and expressed as $\mathrm{nmol} \mathrm{H}_{2} \mathrm{O}_{2} \cdot \mathrm{mg}^{-1}$ Pro $\cdot \mathrm{min}^{-1}$.

\section{Nitrogen Metabolism Enzyme Assay}

Samples of $0.3 \mathrm{~g}$ frozen leaf were powdered in liquid $\mathrm{N}_{2}$ and homogenized with $6 \mathrm{~mL} 50 \mathrm{mM}$ Tris- $\mathrm{HCl}$ buffer $(\mathrm{pH}=8.0)$ containing $2 \mathrm{mM} \mathrm{Mg}^{2+}, 2 \mathrm{mM}$ DTT, and $0.4 \mathrm{M}$ sucrose. The homogenate was centrifuged at $8000 \mathrm{rpm}$ for $10 \mathrm{~min}$ at $4^{\circ} \mathrm{C}$, and the supernatant was used for determination of the activities of GS, GOGAT, and glutamate dehydrogenase (GDH). The reactions were performed in $3 \mathrm{~mL}$ (final volume) of the media indicated below.

Glutamine synthase activity was determined as the method described in Zhang et al. (1997) with some modifications. The reaction mixture contained hydroxylamine hydrochloride buffer (pH7.4). After incubation of the mixture at $37^{\circ} \mathrm{C}$ for $30 \mathrm{~min}$, the reaction was terminated by adding acidic $\mathrm{FeCl}_{3}$ (0.37 $\mathrm{M} \mathrm{FeCl}_{3}$ and 0.2 M TCA in $0.6 \mathrm{M} \mathrm{HCl}$ ). Samples were centrifuged at $8000 \mathrm{rpm}$ for $10 \mathrm{~min}$, and the absorbance at $540 \mathrm{~nm}\left(\mathrm{~A}_{540}\right)$ was measured chromometrically. The blank was absence of hydroxylamine hydrochloride, and the activity of GS was expressed indirectly as $\mathrm{A}_{540} \cdot \mathrm{mg}^{-1} \mathrm{Pro} \cdot \mathrm{h}^{-1}$.

Glutamate synthase activity was assayed at $30^{\circ} \mathrm{C}$ as the method described in Singh and Srivastava (1986). The reaction mixture consisted of $10 \mu \mathrm{mol} \alpha$-ketoglutarate, $1 \mu \mathrm{mol}$ potassium chloride, $37.5 \mu \mathrm{mol}$ Tris-HCl buffer ( $\mathrm{pH}$ 7.6), 0.6 $\mu \mathrm{mol} \mathrm{NADH}$, $8 \mu \mathrm{mol} \mathrm{L}$-glutamine and $0.3 \mathrm{~mL}$ enzyme. The absorbance at $340 \mathrm{~nm}$ was monitored for $300 \mathrm{~s}$. The activity of GOGAT was estimated using the molar extinction coefficient of $\mathrm{NADH}$ (6.22 $\left.\mathrm{mM}^{-1} \cdot \mathrm{cm}^{-1}\right)$, and expressed as $\mathrm{nmol} \mathrm{NADH} \cdot \mathrm{mg}^{-1}$ Pro $\cdot \mathrm{min}^{-1}$.

Glutamate dehydrogenase activity was determined as the method described in Loulakakis and Roubelakis-Angelakis (1990). The reaction mixture contained $300 \mu \mathrm{mol}$ Tris- $\mathrm{HCl}$ buffer ( $\mathrm{pH} 8.0$ ), $600 \mu \mathrm{mol}$ ammonium chloride, $3 \mu \mathrm{mol}$ calcium chloride, $0.6 \mu \mathrm{mol} \mathrm{NADH}$, and $0.1 \mathrm{~mL}$ enzyme. The reaction was started by adding enzyme extract and carried out at $30^{\circ} \mathrm{C}$. The absorbance at $340 \mathrm{~nm}$ was monitored for $300 \mathrm{~s}$, and the activity of GDH was expressed as nmol NADH. $\mathrm{mg}^{-1}$ Pro $\cdot \mathrm{min}^{-1}$.

\section{Estimation of Nitrate, Ammonium, and Total Nitrogen}

For estimation of nitrate and ammonium, $0.1 \mathrm{~g}$ fresh leaf samples were extracted with $25 \mathrm{~mL}$ distilled water in boiling water bath for $15 \mathrm{~min}$, and then filtered using ashless filter paper. Nitrate content was determined according to the method described by Cataldo et al. (1975). The reaction mixture consisted of $0.1 \mathrm{~mL}$ filtrate and $0.4 \mathrm{~mL} \mathrm{5 \%}$ salicylic acid in concentrated $\mathrm{H}_{2} \mathrm{SO}_{4}$. After 15 min of cooling at room temperature, $9.5 \mathrm{~mL} 2 \mathrm{M} \mathrm{NaOH}$ was added slowly to raise the $\mathrm{pH}$ above 12 . After cooling the solution at room temperature, absorbance was recorded at $410 \mathrm{~nm}$. Nitrate content was calculated using a calibration curve prepared with $\mathrm{KNO}_{3}$ and expressed in mg $\mathrm{NO}_{3}{ }^{-} \cdot \mathrm{g}^{-1} \mathrm{Fw}$. Ammonium content was measured using the method of indophenol blue colorimetry at $630 \mathrm{~nm}$ (Zanini, 2001). Ammonium chloride was used as standard. Fine ground leaf dry samples (0.2 g) were digested with $\mathrm{H}_{2} \mathrm{SO}_{4}-\mathrm{H}_{2} \mathrm{O}_{2}$ at $260^{\circ} \mathrm{C}$ for measurement of total N. 


\section{Statistics}

Two-way ANOVAs were conducted to analyze the effects of nitrogen and water. Multiple comparisons were performed using the method of least significant difference (LSD) test. Differences were considered statistically significant when $P<0.05$.

\section{RESULTS}

\section{Xylem Secretion Rate, Transpiration Rate, and Leaf Relative Water Content}

Relative higher xylem secretion rate, transpiration rate $\left(T_{\mathrm{r}}\right)$, and leaf RWC were observed at moderate and high N. Xylem secretion rate and $T_{\mathrm{r}}$ were significantly suppressed by WD at all $\mathrm{N}$ levels, with more reduction at low $\mathrm{N}(89.9$ and 20.6\%) and high $\mathrm{N}$ (84.9 and 21.4\%) versus moderate $\mathrm{N}$ (71.0 and 8.6\%) (Figures 1A,B). However, water condition had no significant effect on RWC at the three $\mathrm{N}$ levels (Figure 1C).

\section{$\mathrm{CO}_{2}$ Assimilation}

Whole plant dry weight (WDW) was not significantly affected by water stress at all three $\mathrm{N}$ levels. Nonetheless, a slight reduction in WDW was observed at moderate and high $\mathrm{N}$ (Figure 2A). Compared to WW, WD significantly decreased $P_{\mathrm{n}}, g_{\mathrm{s}}$ and $C_{\mathrm{i}}$ at low $\mathrm{N}$, but these parameters showed no significant differences between WW and WD at moderate $\mathrm{N}$ (Figures 2B-D). Although WD also significantly reduced $g_{\mathrm{s}}$ and $C_{\mathrm{i}}$ at high $\mathrm{N}$, the reduction of $P_{\mathrm{n}}$ was slight $(P>0.05)$. The $A-C_{\mathrm{i}}$ curve analysis showed that the values of $V_{c, \max }, J_{\max }, T P U$, and $g_{\mathrm{m}}$ were significant higher at moderate and high $\mathrm{N}$ than that at low $\mathrm{N}$ (Figure 3), irrespective WD or not. However, no significant differences were observed between $\mathrm{WW}$ and $\mathrm{WD}$ at all $\mathrm{N}$ levels except $V_{\mathrm{c} \text {, max }}$ at moderate $\mathrm{N}$, in which water stress increased $V_{\mathrm{c}, \max } . V_{\mathrm{c}, \max }, J_{\max }$, and TPU were the highest at high $\mathrm{N}$, whereas $g_{\mathrm{m}}$ was the highest at moderate $\mathrm{N}$.

\section{Chlorophyll Content and Chlorophyll Fluorescence}

Nitrogen had considerable effect on chlorophyll content, whereas WD showed no significant effect on leaf chlorophyll content at low and high N (Table 1). However, WD significantly decreased leaf total chlorophyll, chlorophyll $a$ and carotenoid contents at moderate $\mathrm{N}$. To evaluate the influence of chlorophyll on photosynthesis, chlorophyll fluorescence was further measured. The results in Figure 4 displayed that $F_{\mathrm{v}} / F_{\mathrm{m}}, \Phi_{\mathrm{PSII}}, q P, N P Q$, and ETR were higher at moderate and high $\mathrm{N}$. It is noteworthy that $N P Q$ at moderate and high $\mathrm{N}$ was $\sim 0.5$-fold higher than that at low $\mathrm{N}$ irrespective water stress or not. In contrast, EXC was lower at moderate and high $\mathrm{N}$. Water scarcity merely caused a significant increase in $F_{\mathrm{v}} / F_{\mathrm{m}}$ at moderate $\mathrm{N}$, and a significant reduction in $\Phi_{\text {PSII }}$ and ETR at high $\mathrm{N}$.

\section{Nitrogen Compounds and Activities of Nitrogen Metabolism Enzymes}

Contents of total leaf $\mathrm{N}$ and major nitrogenous compounds (soluble protein, ammonium, proline, and free amino acids)

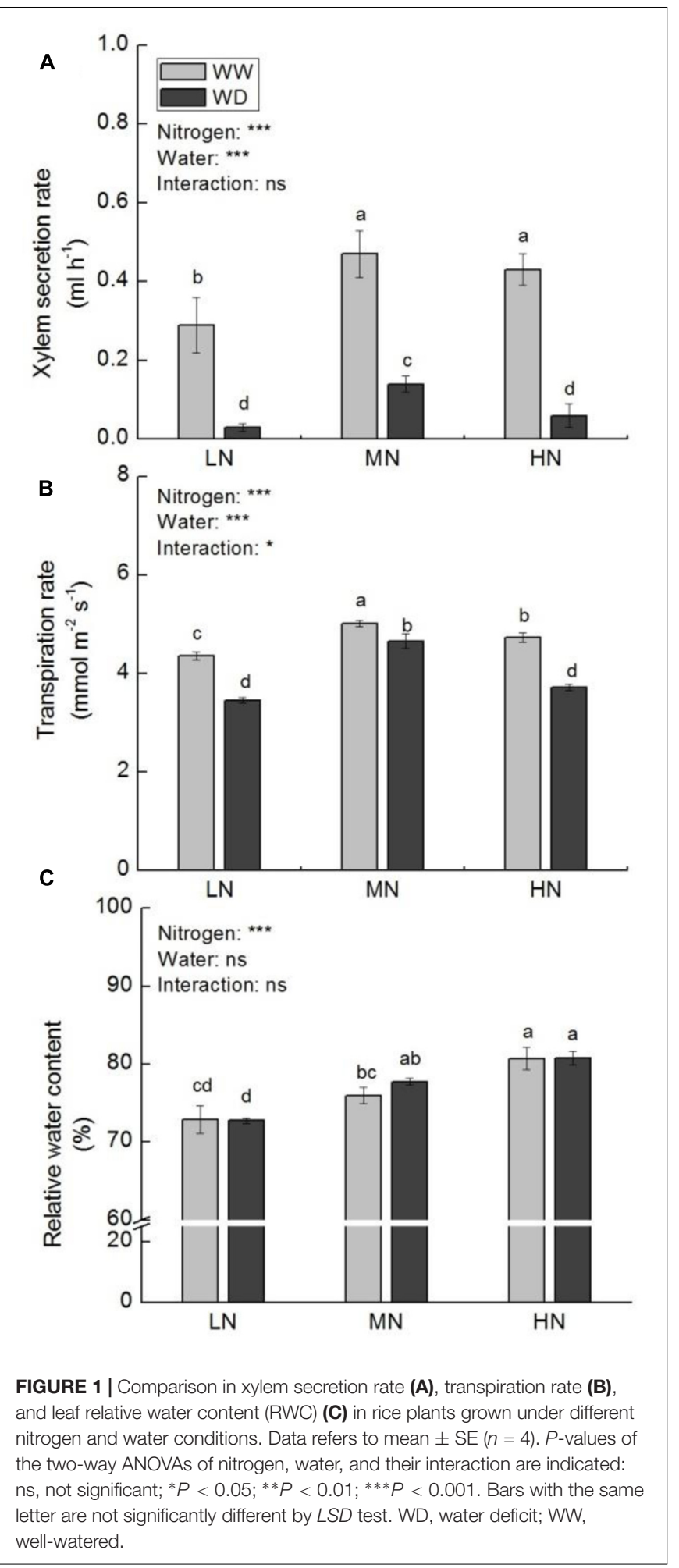

increased with increasing $\mathrm{N}$ level. Total $\mathrm{N}$, soluble protein and ammonium showed no significant difference between WD and WW at the three $\mathrm{N}$ levels (except soluble protein at low $\mathrm{N}$ ) (Figures 5, 6A). However, WD increased nitrate content significantly at low $\mathrm{N}$, but decreased nitrate content significantly 

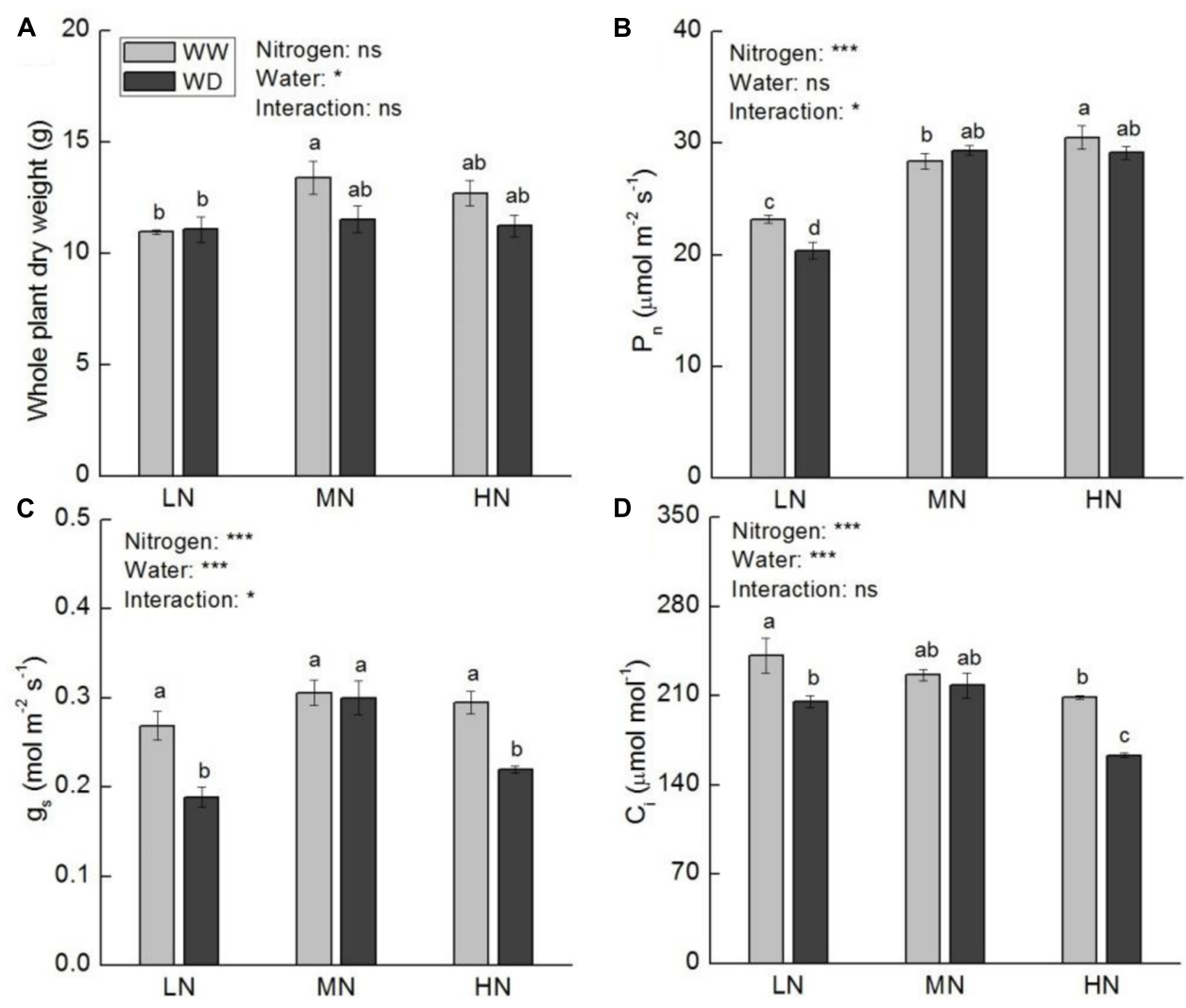

FIGURE 2 | Comparison in whole plant dry weight (A), net photosynthetic rate $\left(P_{\mathrm{n}}, \mathbf{B}\right)$, stomatal conductance $\left(g_{\mathrm{s}}, \mathbf{C}\right)$, and intercellular $\mathrm{CO}_{2}$ concentration $\left(C_{\mathrm{i}}, \mathbf{D}\right)$ in rice plants grown udner different nitrogen and water conditions. Data refers to mean $\pm \mathrm{SE}(n=4)$. $P$-values of the two-way ANOVAs of nitrogen, water, and their interaction are indicated: ns, not significant; ${ }^{*} P<0.05$; ${ }^{*} P<0.01$; ${ }^{* *} P<0.001$. Bars with the same letter are not significantly different by $L S D$ test. WD, water deficit; WW, well-watered.

at moderate and high $\mathrm{N}$ (Figure 6B). Contrary to nitrate, WD increased leaf proline content considerably at moderate $\mathrm{N}$ and high $\mathrm{N}$, while slightly decreased proline content at low $\mathrm{N}$, compared to WW (Figure 6C). Leaf free amino acid content was not significantly affected by WD at low and moderate $\mathrm{N}$, while it was substantially reduced by WD at high N (Figure 6D).

Under WW condition, GS, GOGAT, and GDH activities were decreased with increasing $\mathrm{N}$ level (Figure 7). Water scarcity reduced the activities of GOGAT $(P>0.05)$ and GDH $(P<0.05)$ at low $\mathrm{N}$. whereas their activities were slightly reduced or even increased by WD at moderate and high $\mathrm{N}$. The activity of GS was not significantly affected by WD at all $\mathrm{N}$ levels.

\section{Oxidative Damage and Activities of Ascorbate Peroxidase, Catalase, Superoxide Dismutase, and Glycolate Oxidase}

Lipid peroxidation and $\mathrm{H}_{2} \mathrm{O}_{2}$ content were decreased as the increase of $\mathrm{N}$ level, regardless WD or not (Figure 8). At low $\mathrm{N}$, WD induced significant increases in lipid peroxidation and $\mathrm{H}_{2} \mathrm{O}_{2}$ content, while no significant differences were observed between WW and WD at moderate $\mathrm{N}$ (excepted $\mathrm{H}_{2} \mathrm{O}_{2}$ content) and high $\mathrm{N}$.

Activities of APX, SOD, CAT, and GO at low and moderate $\mathrm{N}$ were higher relative to that at high $\mathrm{N}$, irrespective WD or not (Figure 9). WD reduced the activities of APX $(P>0.05)$, CAT $(P<0.05)$ and GO $(P<0.05)$ at low $\mathrm{N}$, but increased CAT and APX activities at high $\mathrm{N}(P>0.05)$. SOD activity decreased with the increasing $\mathrm{N}$ level, with no significant difference between WW and WD.

\section{DISCUSSION}

\section{Effects of Water Stress on Photosynthesis at Different $\mathbf{N}$ Levels}

It has been widely verified that plant biomass or yield is not always in line with photosynthetic rate of single leaf. Our results showed that plant growth was slightly inhibited by water stress at moderate and high $\mathrm{N}$, whereas their photosynthesis was not affected. The different sensitivity of plant growth and photosynthesis to water stress could contribute to the different performances of biomass and photosynthetic rate in response to water stress. Besides, the trade-off between growth 

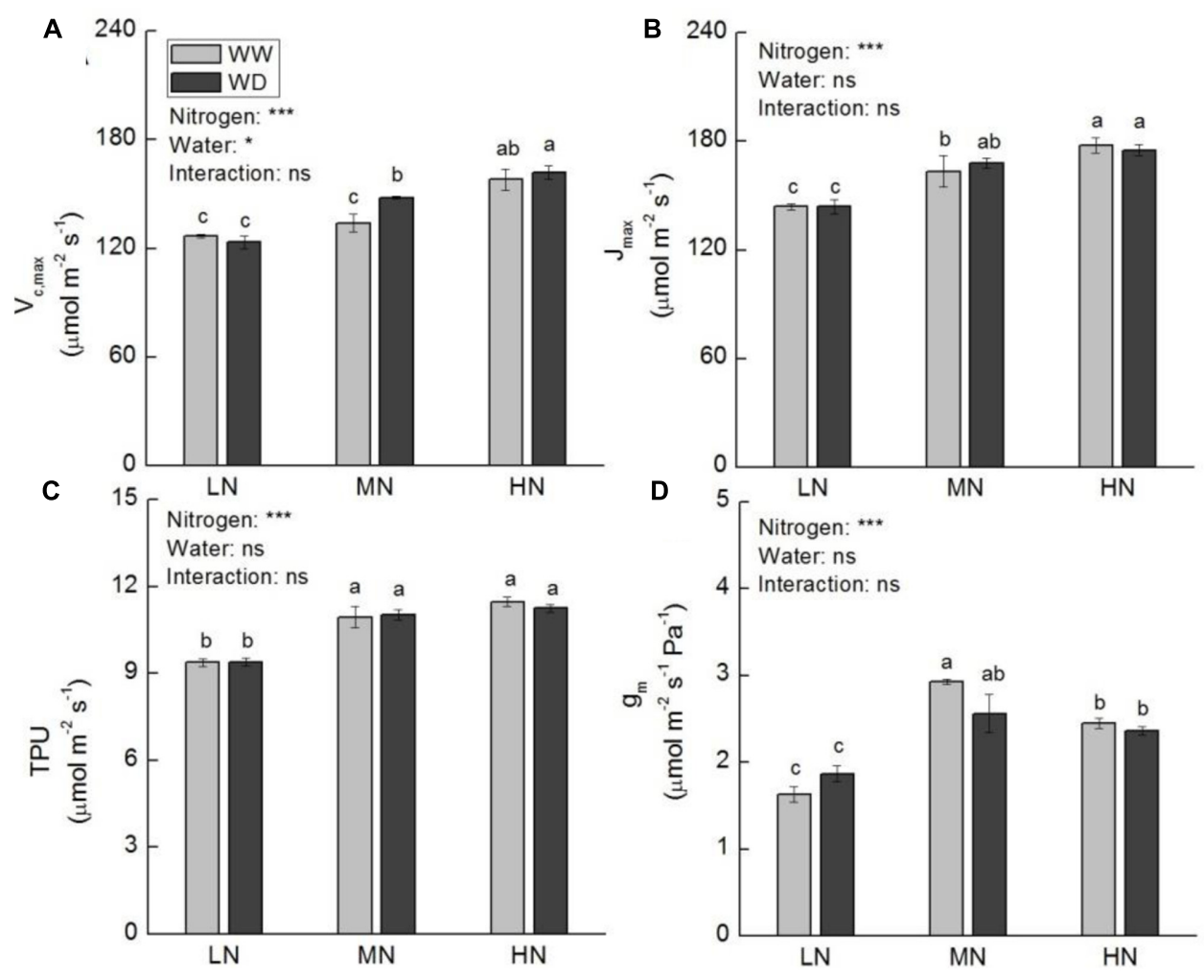

FIGURE 3 | Comparison in maximum carboxylation rate of Rubisco $\left(V_{c, m a x}, \mathbf{A}\right)$, maximum electron transport rate $\left(J_{\max }, \mathbf{B}\right)$, triose phosphate utilization (TPU, C), and mesophyll conductance $(g \mathrm{~m}$, D) of rice plants grown under different nitrogen and water conditions. Data refers to mean $\pm \mathrm{SE}(n=4)$. $P$-values of the two-way ANOVAs of nitrogen, water, and their interaction are indicated: ns, not significant; ${ }^{*} P<0.05$; ${ }^{* *} P<0.01$; ${ }^{* * *} P<0.001$. Bars with the same letter are not significantly different by LSD test. WD, water deficit; WW, well-watered.

and stress defense could also be responsible for the resistance of photosynthesis to water stress (Karasov et al., 2017). The significant effect of nitrogen and water stress interaction on photosynthetic rate implies that $\mathrm{N}$ is essential for regulating the adaptation of photosynthesis to water stress.

Water stress tolerance of plant is significantly governed by its water retention capacity (Gill et al., 2015). Transpiration is the major pathway of water loss from leaves. Generally, plants reduce water loss by partial closing of stomata under water stress conditions. In accordance with xylem secretion rate, transpiration rate was significantly reduced under water stress in this study. As a result, leaf RWC was maintained even under water stress. It has been suggested that higher water acquisition capacity under water stress may contribute to higher photosynthetic rate (Guo et al., 2007; Gao et al., 2010). Although water scarcity reduced active water absorption

TABLE 1 | Comparison in chlorophyll contents of rice plants grown under different nitrogen and water conditions.

\begin{tabular}{|c|c|c|c|c|c|}
\hline Treatment & & $\begin{array}{c}\text { Chlorophyll a } \\
\text { content } / \mathrm{mg} \mathrm{g}^{-1} \mathrm{Fw}\end{array}$ & $\begin{array}{c}\text { Chlorophyll } b \\
\text { content } / \mathrm{mg} \mathrm{g}^{-1} \mathrm{Fw}\end{array}$ & $\begin{array}{c}\text { Carotenoid } \\
\text { content } / \mathrm{mg} \mathrm{g}^{-1} \mathrm{Fw}\end{array}$ & $\begin{array}{l}\text { Total chlorophyll } \\
\text { content } / \mathrm{mg} \mathrm{g}^{-1} \mathrm{Fw}\end{array}$ \\
\hline Low N & WW & $2.83 \pm 0.04 c$ & $0.82 \pm 0.01 c$ & $0.59 \pm 0.01 b$ & $4.23 \pm 0.05 d$ \\
\hline \multirow[t]{2}{*}{ Moderate N } & WW & $3.43 \pm 0.12 b$ & $1.23 \pm 0.02 b$ & $0.69 \pm 0.03 a$ & $5.35 \pm 0.14 b$ \\
\hline & WD & $2.94 \pm 0.09 c$ & $1.44 \pm 0.07 \mathrm{a}$ & $0.54 \pm 0.03 b$ & $4.92 \pm 0.11 c$ \\
\hline High N & WW & $3.69 \pm 0.09 a$ & $1.45 \pm 0.07 a$ & $0.72 \pm 0.02 a$ & $5.86 \pm 0.08 a$ \\
\hline \multirow[t]{2}{*}{$F$-value } & Water & $5.95^{*}$ & $6.55^{*}$ & $5.87^{*}$ & $2.42 \mathrm{~ns}$ \\
\hline & Nitrogen $\times$ water & $7.17^{* *}$ & $2.73 \mathrm{~ns}$ & $8.52^{* *}$ & $5.72^{*}$ \\
\hline
\end{tabular}

Data refers to mean $\pm S E(n=4)$. F-values of the two-way ANOVAs of nitrogen, water, and their interaction are indicated: $n s, n$ not significant; $* P<0.05 ; * * P<0.01$; ${ }^{* * *} P<0.001$. Means in the same column with the same letter are not significantly different by LSD test. WD, water deficit; WW, well-watered. 


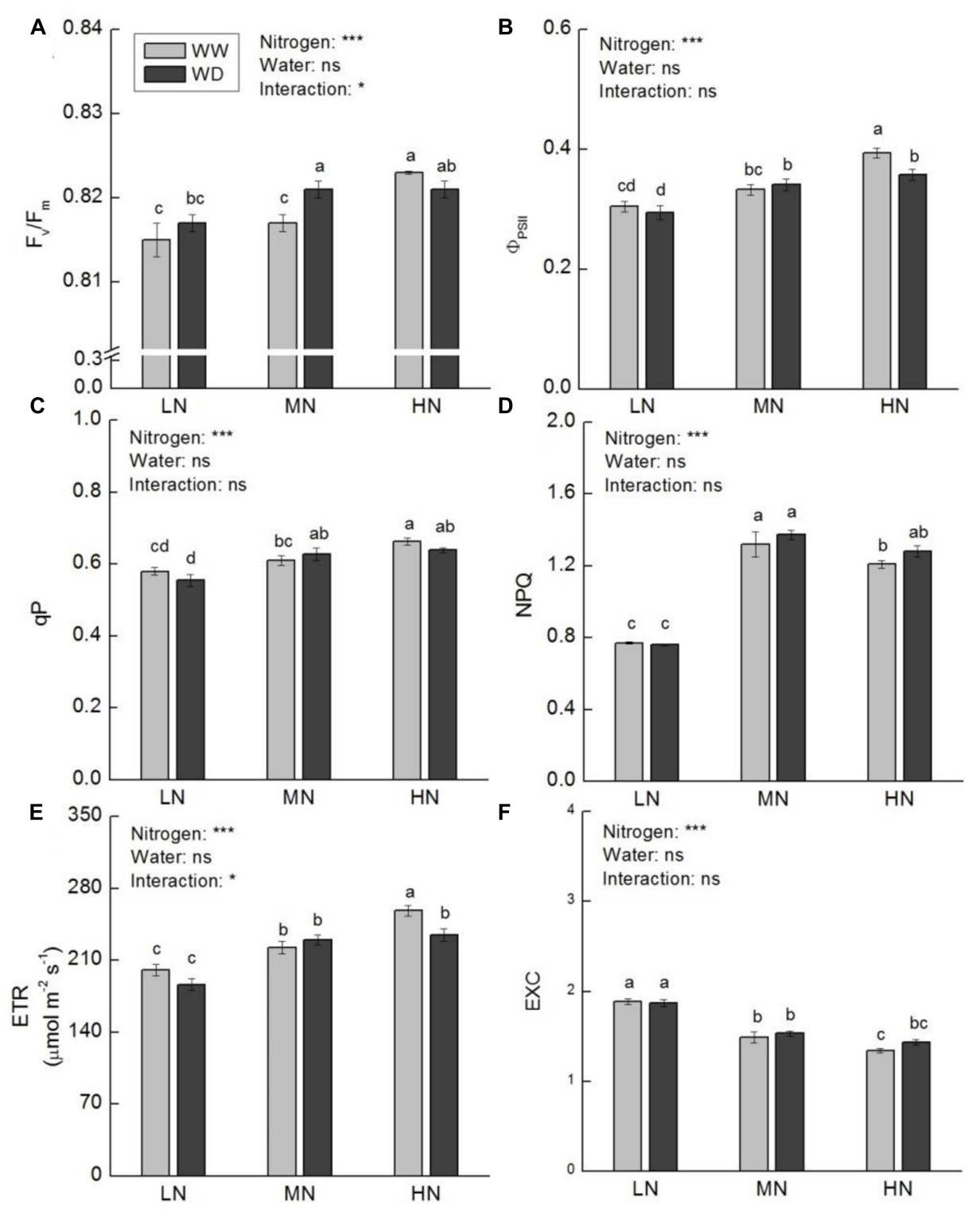

FIGURE 4 | Comparison in chlorophyll fluorescence parameters in rice plants grown udner different nitrogen and water conditions. (A) Maximum quantum yield of PSIl photochemistry. (B) Effective quantum yield of PSIl photochemistry. (C) Photochemical quenching coefficient. (D) Non-photochemical quenching coefficient. (E) Electron transport rate at PSIl level. (F) Relative excessive energy at PSIl level. Data refers to mean \pm SE $(n=4)$. $P$-values of the two-way ANOVAs of nitrogen, water, and their interaction are indicated: ns, not significant; ${ }^{*} P<0.05 ;{ }^{*} P<0.01 ;{ }^{* * *} P<0.001$. Bars with the same letter are not significantly different by $L S D$ test. WD, water deficit; WW, well-watered.

of roots in this study, it remained higher water acquisition capacity at higher $\mathrm{N}$ (Figure 1). This may result from $\mathrm{N}$-mediated higher root activity. It has been reported that higher $\mathrm{N}$ application increased rice root activity (Xu et al., 2015). In another study, we also observed that rice root activity was higher at high $\mathrm{N}$ even in the situation of water stress (data not published).

Stomata control water and gas exchange between leaves and ambient air. Trade-off between water loss and gas exchange is crucial for plants to maintain photosynthetic capacity under WD condition (Manzoni et al., 2013). Although partial closure of stomata is paramount for prohibiting water loss to maintain water balance in plant, stomatal closure increases the resistance of $\mathrm{CO}_{2}$ diffusion from ambient air to intercellular airspace $\left(g_{\mathrm{s}}\right)$, as well as from intercellular airspace to carboxylation site $\left(g_{\mathrm{m}}\right)$. To date, the relative importance of $g_{\mathrm{s}}$ and $g_{\mathrm{m}}$ in photosynthesis remains controversial (Niinemets et al., 2009; Xiong et al., 2015; Barbour and Kaiser, 2016). In the current study, $g_{\mathrm{s}}$ could be more important than $g_{\mathrm{m}}$ for regulating photosynthesis under water stress. Water stress and its interaction with nitrogen showed significant effects on $g_{s}$, and a stomatal limitation to photosynthesis occurred at low $\mathrm{N}$, suggesting that $\mathrm{N}$ is a pivotal 
factor in regulating stomata movement under water scarcity. Higher $\mathrm{N}$ could increase the sensitivity of stomata to water stress to prohibit (or alleviate) stomatal limitation of photosynthesis (Otoo et al., 1989). Hacke et al. (2010) proposed that aquaporin may take part in the regulation of $\mathrm{N}$ on $g_{s}$. However, more studies are needed to identify the role that $\mathrm{N}$ plays in the regulation of stomatal movement. It is speculated that $g_{\mathrm{m}}$ is not the main factor affecting photosynthetic rate under water stress in this study, as it was affected by nitrogen rather than water deficiency. $g_{\mathrm{m}}$ is determined by both complex leaf anatomical structure and biochemical factors (Giuliani et al., 2013). It is postulated that the unchanged $g_{\mathrm{m}}$ under water stress could be due to the fact that short-term WD treatment is not long enough to change the leaf anatomical structure. Besides, the quick restoration of $g_{\mathrm{m}}$ during the acclimation of water stress may also result in the undifferentiated $g_{\mathrm{m}}$ between water treatments (Galle et al., 2010).

$V_{c, \max }, J_{\max }$, and TPU reflect the three biochemical factors limiting photosynthesis under light-saturation condition: (i) the amount and activity of Rubisco; (ii) the regeneration rate of RuBP; and (iii) the utilization of triose phosphate and regeneration of $\mathrm{Pi}$ for photophosphorylation, respectively (Farquhar et al., 1980; von Caemmerer and Farquhar, 1981). Rubisco represents the majority of $\mathrm{N}$ invested in photosynthesis. It can excess a quarter of leaf $\mathrm{N}$ and account for as much as half of soluble protein (Parry et al., 2013). It is the rate-limiting enzyme of $\mathrm{CO}_{2}$ fixation in $\mathrm{C}_{3}$ plants. It has been reported that $V_{\mathrm{c} \text {,max }}$ was affected by water stress only when the stress becomes severe (Bota et al., 2004; Rivero et al., 2009; Galle et al., 2010). Our results suggest that Rubisco could be one of the factors affecting photosynthetic rate even under moderate water stress. Furthermore, the effect of water stress on $V_{c, \max }$ is $\mathrm{N}$ level related; higher $\mathrm{N}$ is beneficial to increase or maintenance of Rubisco activity under moderate water scarcity condition.

It should be noted that WD substantially reduced $g_{\mathrm{s}}$ and $C_{\mathrm{i}}$ at high $\mathrm{N}$ as well. Concurrently, the decrease of $\Phi_{\text {PSII }}$ and ETR were also observed at high $\mathrm{N}$. Due to $P_{\mathrm{n}}$ was not affected in WD, the reduction of $\Phi_{\text {PSII }}$ and ETR could be an adaptive strategy of photosynthesis rather than an indicator of damage in response to water stress.

\section{Effects of Water Stress on N Assimilation at Different $\mathbf{N}$ Levels}

Nitrogen assimilation is tightly linked with carbon metabolism in the fundamental biochemical pathways in plants. $\mathrm{N}$ assimilation, especially the reduction of nitrate, is a highly energy dependent reaction (Bloom et al., 2010). Incorporation of inorganic $\mathrm{N}$ into amide and amino acid consumes energy and reducing equivalents produced in photosynthesis, mitochondrial oxidative metabolism, or other cytosolic reactions, depending on the site of reaction (Sunil et al., 2013). Reduction of nitrate in leaves could use the excessive reducing power derived from photosynthesis, and it is more efficient than the reduction which takes place in roots in water stress situation (GonzalezDugo et al., 2010). Thus, $\mathrm{N}$ assimilation acts as an important alternative sink of electron and excessive excited energy to minimize photoinhibition and photodamage of photosynthesis, and to stimulate $\mathrm{CO}_{2}$ assimilation under conditions of stomatal limitation imposed by osmotic stress (Yi et al., 2014).

The effects of water stress on leaf $\mathrm{N}$ status are erratic, with increase, decrease, or constant in different species (Jangam and Raghuram, 2015). In this study, total leaf $\mathrm{N}$ content was not affected by water stress at all the three $\mathrm{N}$ levels; however, water stress induced alterations of some nitrogenous compounds (e.g., nitrate, protein, proline, and amino acid) in rice leaf were $\mathrm{N}$ level dependent. Nitrate is an important $\mathrm{N}$ pool in plant (Han et al., 2016). When $\mathrm{N}$ supply is sufficient, a considerable amount of nitrate is stored in vacuoles, which can be reutilized when $\mathrm{N}$ supply is limited (e.g., water stress induced decrease of $\mathrm{N}$ uptake). The result in this study suggests that sufficient $\mathrm{N}$ supply facilitates assimilation of stored nitrate under WD condition, which could partly contribute to mitigating photoinhibition of photosynthesis caused by water stress. Water stress can lead to proteolytic breakdown of protein and consequently result in accumulation of amino acids (Akinci and Sösel, 2012). However, water stress did not lead to a decline in soluble protein in our study. The variation of amino acids resulted from water stress at different $\mathrm{N}$ levels is more likely to reflect the changes in $\mathrm{N}$ uptake and assimilation, and turnover of amino acid, e.g., proline synthesis (Walch-Liu et al., 2005). It is generally accepted that proline is a preferred soluble organic osmolyte in many plants, as well as an important contributor to stabilize membrane structure by buffering cellular redox potential (Szabados and Savouré, 2010; Singh et al., 2016). Nevertheless, the significance of proline accumulation in osmotic adjustment is not always apparent (Szabados and Savouré, 2010). In some studies, accumulation of proline seems to be a symptom of injury rather than an indicator of stress tolerance (Hoai et al., 2003). While in this study, water stress induced increase in proline content at moderate and high $\mathrm{N}$ serves more likely as an osmotica to protect rice photosynthesis against water stress. The adverse changes of nitrate and proline induced by water stress further suggest that sufficient $\mathrm{N}$ supply provides substantial foundation for improving the resistance of photosynthesis to water stress in rice, which may rely greatly on $\mathrm{N}$ assimilation.

Ammonium acts at the center of $\mathrm{N}$ flow in plant leaf (Thomsen et al., 2014). Given a large amount of ammonium is produced as a result of protein hydrolysis and photorespiration, it is essential that toxic ammonium be immediately reassimilated into organic molecules for nitrogen cycling (Masclaux-Daubresse et al., 2006). GS, GOGAT, and GDH are important enzymes involving in $\mathrm{N}$ recycling in plant. It has been widely reported that photosynthesis and activities of key enzymes related to nitrogen assimilation were consistently down-regulated under water stress condition (Garg et al., 2001; Xu and Zhou, 2006; Pinheiro and Chaves, 2011). However, our results displayed that the response of activities of $\mathrm{N}$ assimilation enzymes to water stress was $\mathrm{N}$ level dependent. These enzymes were more sensitive to water stress at low $\mathrm{N}$, and water stress had a greater effect on GDH than on GS and GOGAT. Since GDH and GS-GOGAT pathway play distinct roles in N cycle (MasclauxDaubresse et al., 2006), it is implied that other $\mathrm{N}$ metabolic 

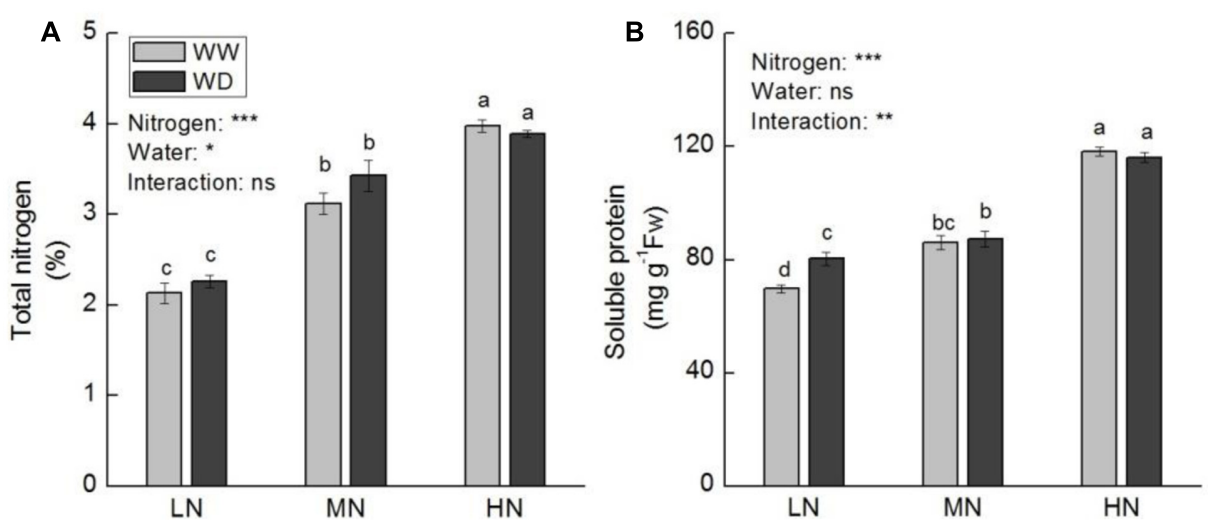

FIGURE 5 | Comparison in the contents of total leaf nitrogen (A) and soluble protein (B) in rice plants grown udner different nitrogen and water conditions. Data refers to mean \pm SE $(n=4)$. $P$-values of the two-way ANOVAs of nitrogen, water, and their interaction are indicated: ns, not significant; $* P<0.05$; $* * P<0.01$; $* * * P<0.001$. Bars with the same letter are not significantly different by $L S D$ test. WD, water deficit; WW, well-watered.

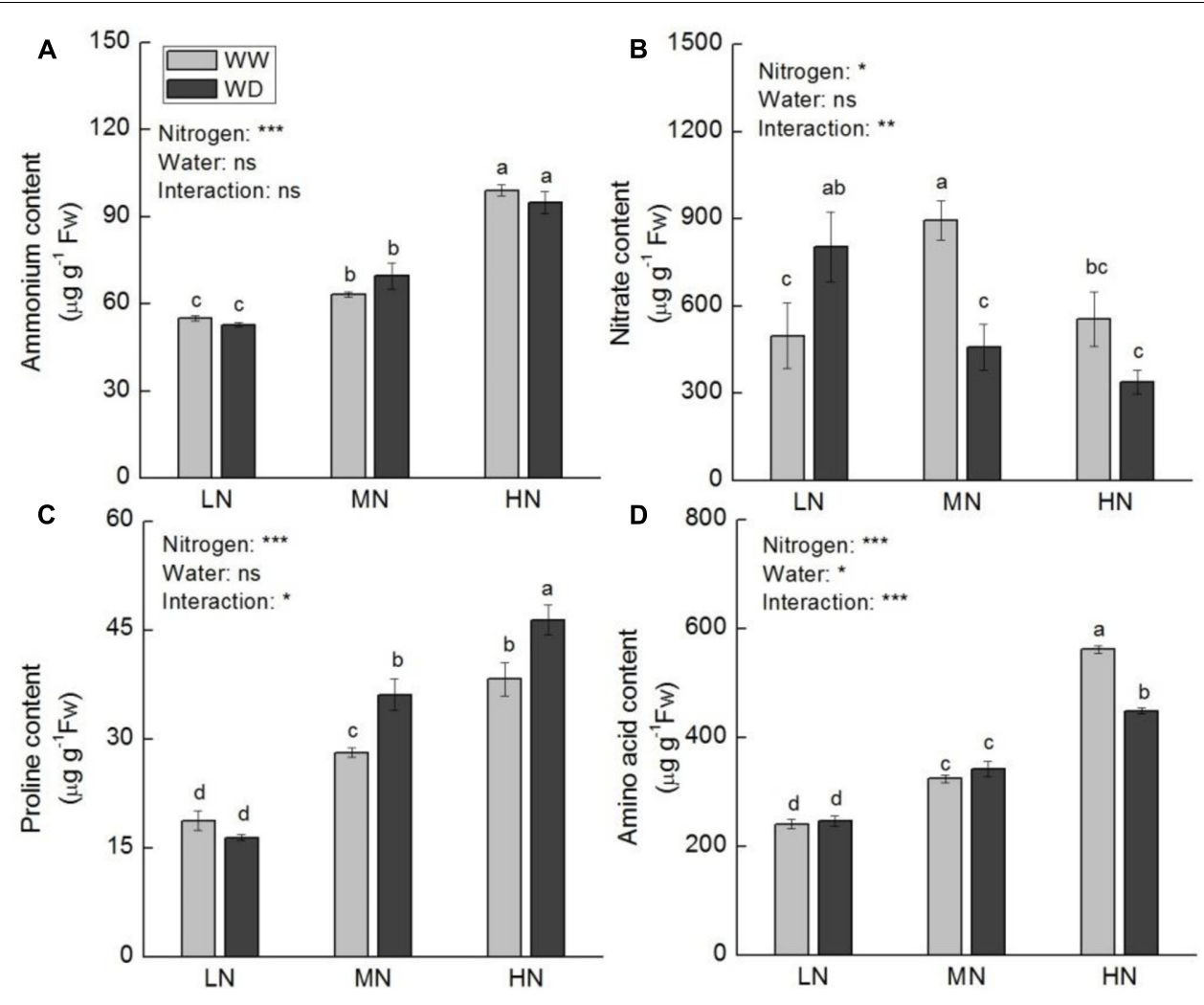

FIGURE 6 | Comparison in the contents of ammonium (A), nitrate (B), proline (C), and free amino acid (D) in rice plants grown udner different nitrogen and water conditions. Data refers to mean \pm SE $(n=4)$. $P$-values of the two-way ANOVAs of nitrogen, water, and their interaction are indicated: $n s$, not significant; ${ }^{*} P<0.05$; ${ }^{* *} P<0.01 ;{ }^{* * *} P<0.001$. Bars with the same letter are not significantly different by LSD test. WD, water deficit; WW, well-watered.

processes besides primary $\mathrm{N}$ assimilation are regulated by water stress. In addition to ammonium assimilation, Boussama et al. (1999) proposed the function of GDH in the synthesis of proline by providing Glu under stress condition. Water stress induced increase in soluble protein and decrease in proline at low $\mathrm{N}$ (Figures 5B, 6C) could be partially resulted from the decline in GDH activity. It is suggested that GDH is essential for the acclimation of rice photosynthesis to water stress. GO is a key enzyme in photorespiration, which catalyzes the oxidation of glycolate to glyoxylate. The latter is in turn converted to glycine by transamination. Glycine is further converted to serine in mitochondria by transamination to release ammonia. It is 


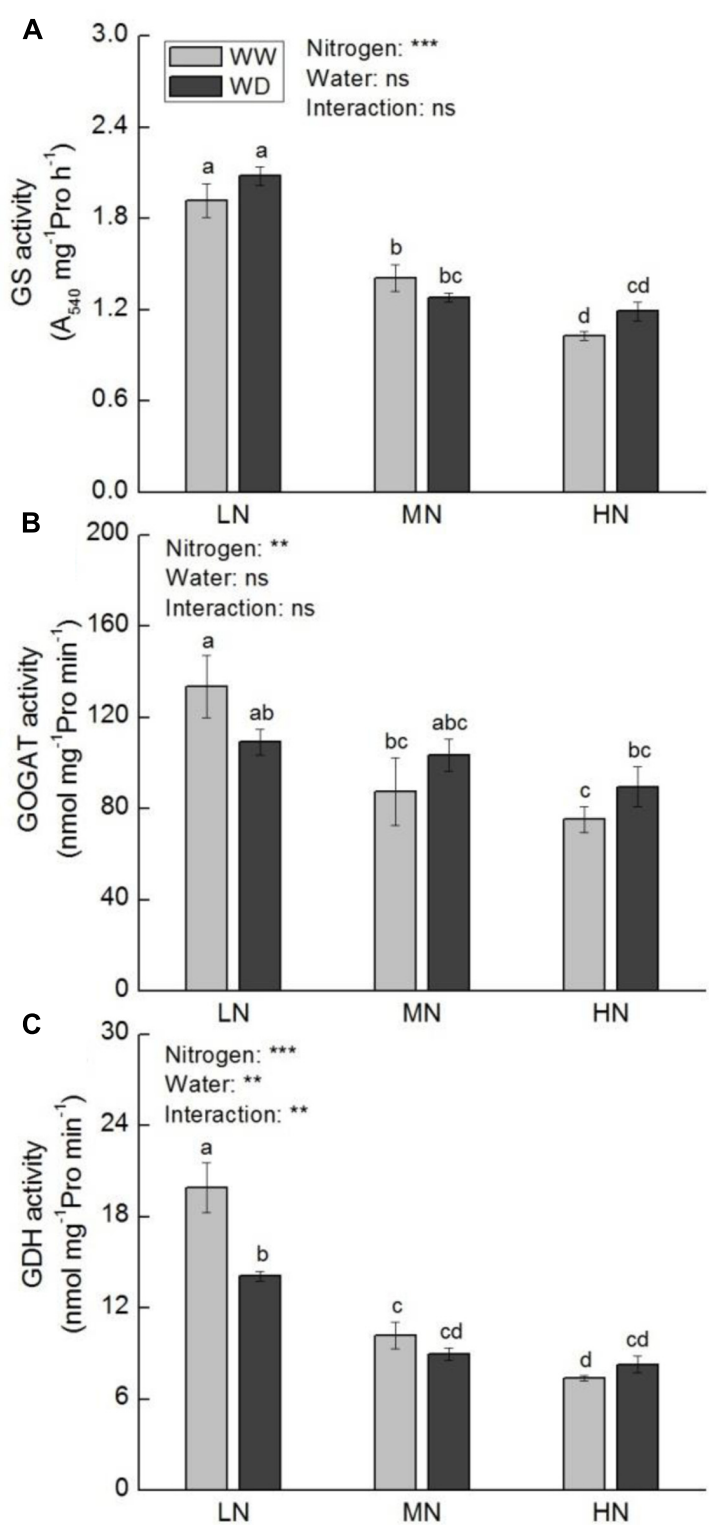

FIGURE 7 | Comparison in activities of glutamine synthase (GS, A), $\mathrm{NADH}$-glutamate synthase (NADH-GOGAT, B), and NADH-glutamate dehydrogenase $(\mathrm{NADH}-\mathrm{GDH}, \mathbf{C})$ in rice plants grown under different nitrogen and water conditions. Data refers to mean $\pm \operatorname{SE}(n=4)$. $P$-values of the two-way ANOVAs of nitrogen, water, and their interaction are indicated: ns, not significant; ${ }^{*} P<0.05 ;{ }^{*} P<0.01 ;{ }^{* *} P<0.001$. Bars with the same letter are not significantly different by $L S D$ test. WD, water deficit; WW, well-watered.

well known that in non-leguminous $\mathrm{C}_{3}$ plants, the flux of ammonia released during photorespiration could be more than 10 -fold the rate of primary assimilation (Masclaux-Daubresse et al., 2006). The photorespiratory $\mathrm{N}$ cycle contributes to the metabolism of certain amino acids, e.g., Gln, Glu, Ser, and Gly (Igarashi et al., 2006). Decrease in photorespiration will lead to decline in photosynthesis and nitrate assimilation (Bloom et al., 2010; Silva et al., 2015). The results of GO activity together with $\mathrm{N}$ assimilation enzymes and nitrogenous compounds reveal that nitrate and ammonium assimilation play important roles in adaption of rice photosynthesis to water stress, protecting photosynthesis from inhibition by water scarcity.

\section{Effects of Water Stress on Antioxidant Capacity at Different N Levels}

Water stress induced disequilibrium between light energy absorption and utilization will cause the accumulation of ROS, and consequently increase the photooxidative damage to photosynthesis, performed as decline in $P_{\mathrm{n}}$ and enhancement in peroxidation of cell membrane (Hassan et al., 2012; Gill et al., 2015). Therefore, maintenance of appropriate level of ROS in cell and prevention of irreversible damage to photosynthetic machinery is essential for regular photosynthesis (Chaves and Oliveira, 2004; Sunil et al., 2013). There are multiple effective mechanisms to avoid excessive accumulation of ROS in plants, including avoidance of excessive light energy absorption, enhancement of energy dissipation, and improvement of antioxidant systems (Silva et al., 2015; Chang et al., 2016). Studies with pigment mutants revealed that photosynthetic pigment reduction does not necessarily lead to decline in photosynthetic rate. Reduced pigment content could enable plants to avoid excessive light energy absorption and improve quantum efficiency of PSII and electron transport rate, leading to higher photosynthetic rate (Wu et al., 2014; Gu et al., 2017). Reduced $F_{\mathrm{v}} / F_{\mathrm{m}}$ reflects the photoinhibition of PSII (Misra et al., 2012). In this study, the reduced chlorophyll content and increased $F_{\mathrm{V}} / F_{\mathrm{m}}$ at moderate $\mathrm{N}$ in response to water stress indicate that alteration in chlorophyll content is an efficient strategy to prevent photosynthesis from photoinhibition. NPQ is a common mechanism that plant dissipates excessive excited energy under high light, high $\mathrm{N}$, and water stress. The increased $N P Q$ with $\mathrm{N}$ level was in parallel with decrease in TBARS and $\mathrm{H}_{2} \mathrm{O}_{2}$ contents, suggesting that NPQ is important for preventing photosynthesis from photodamage. Water stress can modulate activities of antioxidant enzymes in plants (Gill et al., 2015). In addition, plant antioxidant capacity is depended greatly upon $\mathrm{N}$ availability. Higher $\mathrm{N}$ improves stress tolerance of plants via enhancement of the antioxidant ability and inhibition of lipid peroxidation (Fu and Huang, 2003). On the contrary, low $\mathrm{N}$ attenuates ROS scavenging system and increases oxidative stress in leaves (Ramalho et al., 1998). Our results are consistent with those findings that low $\mathrm{N}$ led to significant higher lipid peroxidation and $\mathrm{H}_{2} \mathrm{O}_{2}$ content compared to moderate and high N. Besides, water scarcity aggravated oxidative injure to membrane at low N. Xu et al. (2014) proposed that proline could protect antioxidative enzymes. Similarly, in this study, the responses of CAT and APX activities to water stress were consistent with proline content (except moderate $\mathrm{N}$ ). The results indicate that higher level of $\mathrm{N}$ metabolism may have contributed to water stress tolerance of photosynthesis in rice by preventing cell membrane damage, and this could as a result of effective energy dissipation and ROS scavenging system. 

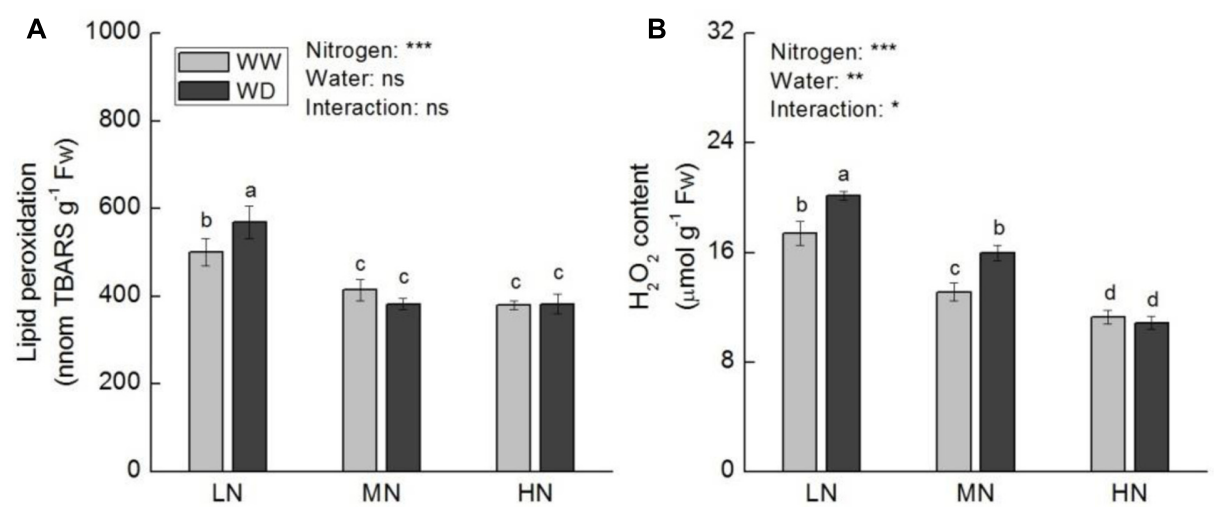

FIGURE 8 | Comparison in leaf lipid peroxidation (A) and hydrogen peroxide (B) in rice plants grown udner different nitrogen and water conditions. Data refers to mean \pm SE $(n=4)$. $P$-values of the two-way ANOVAs of nitrogen, water, and their interaction are indicated: ns, not significant; ${ }^{*} P<0.05$; ${ }^{* *} P<0.01 ;{ }^{* * *} P<0.001$. Bars with the same letter are not significantly different by LSD test. WD, water deficit; WW, well-watered.
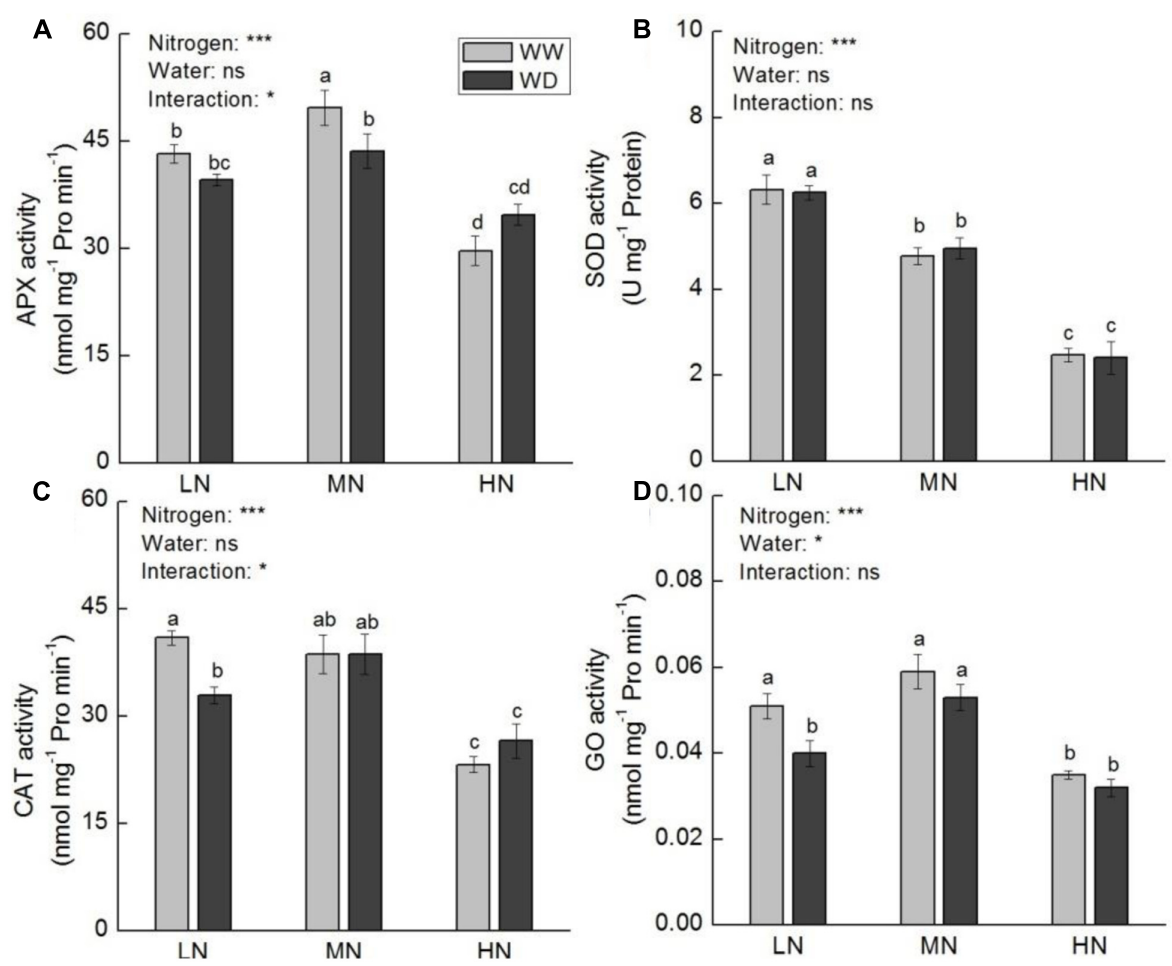

FIGURE 9 | Comparison in activities of ascorbate peroxidase (APX, A), superoxide dismutase (SOD, B), catalase (CAT, C), and glycolate oxidase (GO, D) in rice plants grown udner different nitrogen and water conditions. Data refers to mean \pm SE $(n=4)$. $P$-values of the two-way ANOVAs of nitrogen, water, and their interaction are indicated: ns, not significant; ${ }^{*} P<0.05$; ${ }^{* *} P<0.01$; and ${ }^{* * *} P<0.001$. Bars with the same letter are not significantly different by $L S D$ test. WD, water deficit; WW, well-watered.

Photorespiration is a significant and important component of physiological process overlapping other ways of primary metabolism (Peterhansel and Maurino, 2011). The reactions in photorespiration, e.g., the conversion of hydroxypyruvate to glycerate and the subsequent to PGA, and the re-fixation of $\mathrm{NH}_{4}{ }^{+}$deriving from glycine decarboxylation, require energy (ATP) and reducing equivalents $[\mathrm{NAD}(\mathrm{P}) \mathrm{H}]$ (Peterhansel and
Maurino, 2011). Accordingly, photorespiration is recognized as a vital mechanism for mitigation of ROS generation and photoinhibition that can occur under water stress condition (Guan and Gu, 2009; Peterhansel et al., 2010; Zhang et al., 2016). CAT has positive feedback on GO activity, for CAT scavenges $\mathrm{H}_{2} \mathrm{O}_{2}$ derived from $\mathrm{GO}$ catalyzed conversion of glycolate to glyoxylate (Zelitch, 1990). The significant reduction in GO 
activity at low $\mathrm{N}$ could be partially by virtue of reduced CAT activity.

\section{CONCLUSION}

Our findings reveal that higher $\mathrm{N}$ increases adaptability of rice photosynthesis to water stress via the pathways including: (i) mitigation of stomatal limitation to photosynthesis and maintenance of higher Rubisco activity; (ii) maintained or increased antioxidant enzymes activities and higher excessive energy dissipation capacity; and (iii) increased nitrate and ammonium assimilation and synthesis of proline. Nitrogen metabolism plays a central role in these pathways. The results suggest that the resistance of rice photosynthesis to WD could be improved by manipulation of key enzymes involving in $\mathrm{N}$ metabolism.

\section{REFERENCES}

Akinci, S., and Sösel, D. M. (2012). "Plant water-stress response mechanisms”, in Water Stress, ed. I. M. M. Rahman (Rijeka: InTech), 15-42.

Atkinson, L. J., Sherlock, D. J., and Atkin, O. K. (2014). Source of nitrogen associated with recovery of relative growth rate in Arabidopsis thaliana acclimated to sustained cold treatment. Plant Cell Environ. 38, 1023-1034. doi: $10.1111 /$ pce. 12460

Baker, A. L., and Tolbert, N. E. (1966). Glycolate oxidase (ferredoxin-containing form). Methods Enzymol. 9, 339-340. doi: 10.1016/0076-6879(66)09069-4

Barbour, M. M., and Kaiser, B. N. (2016). The response of mesophyll conductance to nitrogen and water availability differs between wheat genotypes. Plant Sci. 251, 119-127. doi: 10.1016/j.plantsci.2016.03.012

Bates, L. S., Waldren, R. P., and Teare, I. D. (1973). Rapid determination of free proline for water-stress studies. Plant Soil 39, 205-207. doi: 10.1007/ BF00018060

Bloom, A. J., Burger, M., Asensio, J. S. R. A., and Cousins, A. B. (2010). Carbon dioxide enrichment inhibits nitrate assimilation in wheat and Arabidopsis. Science 328, 899-902. doi: 10.1126/science. 1186440

Bota, J., Medrano, H., and Flexas, J. (2004). Is photosynthesis limited by decreased Rubisco activity and RuBP content under progressive water stress? New Phytol. 162, 671-681. doi: 10.1111/j.1469-8137.2004.01056.x

Boussama, N., Ouariti, O., Suzuki, A., and Ghorbel, M. H. (1999). Cd-stress on nitrogen assimilation. J. Plant Physiol. 155, 310-317. doi: 10.1016/S01761617(99)80110-2

Bouman, B. A. M., and Tuong, T. P. (2001). Field water management to save water and increase its productivity in irrigated lowland rice. Agric. Water Manag. 49, 11-30. doi: 10.1016/S0378-3774(00)00128-1

Brennan, T., and Frenkel, C. (1977). Involvement of hydrogen peroxide in the regulation of senescence in pear. Plant Physiol. 59, 411-416. doi: 10.1104/pp. 59.3.411

Cataldo, D. A., Haroon, M., Schrader, L. E., and Youngs, V. L. (1975). Rapid colorimetric determination of nitrate in plant tissue by nitration of salicylic acid. Commun. Soil Sci. Plant Anal. 6, 71-80. doi: 10.1080/00103627509366547

Chang, Z., Liu, Y., Dong, H., Teng, K., Han, L., and Zhang, X. (2016). Effects of cytokinin and nitrogen on drought tolerance of creeping bentgrass. PLOS ONE 11:e0154005. doi: 10.1371/journal.pone.0154005

Chardon, F., Noël, V., and Masclaux-Daubresse, C. (2012). Exploring NUE in crops and in Arabidopsis ideotypes to improve yield and seed quality. J. Exp. Bot. 63, 3401-3412. doi: 10.1093/jxb/err353

Chaves, M. M., and Oliveira, M. M. (2004). Mechanisms underlying plant resilience to water deficits: prospects for water-saving agriculture. J. Exp. Bot. 55, 2365-2384. doi: 10.1093/jxb/erh269

Chen, C. Z., Lv, X. F., Li, J. Y., Yi, H. Y., and Gong, J. M. (2012). Arabidopsis NRT1.5 is another essential component in the regulation of nitrate reallocation and stress tolerance. Plant Physiol. 159, 1582-1590. doi: 10.1104/pp.112.199257

\section{AUTHOR CONTRIBUTIONS}

$\mathrm{CZ}$ collected the samples, analyzed the samples, and drafted the manuscript. XC made a contribution to design of the work and to draft the manuscript. JjH collected the samples and analyzed the samples. LZ and JZ analyzed the data and revised the manuscript. $\mathrm{JlH}$ and QJ conceived and designed this work. All authors read and approved the manuscript.

\section{ACKNOWLEDGMENT}

We thank the Zhejiang Provincial Natural Science Foundation of China (No. LQ15C130004), National Basic Research Program of China (No. 2015CB150502), and National Natural Science Foundation of China (No. 31172032, 31270035) for financial support.

Chen, G. X., and Asada, K. (1989). Ascorbate peroxidase in tea leaves: occurrence of two isozymes and the differences in their enzymatic and molecular properties. Plant Cell Physiol. 30, 987-998. doi: 10.1093/oxfordjournals.pcp.a077844

Dodd, I. C., Puértolas, J., Huber, K., Pérez-Pérez, J. G., Wright, H. R., and Blackwell, M. S. A. (2015). The importance of soil drying and re-wetting in crop phytohormonal and nutritional responses to deficit irrigation. J. Exp. Bot. 66, 2239-2252. doi: 10.1093/jxb/eru532

Fang, X. Z., Tian, W. H., Liu, X. X., Lin, X. Y., Jin, C. W., and Zheng, S. J. (2016). Alleviation of proton toxicity by nitrate uptake specifically depends on nitrate transporter 1.1 in Arabidopsis. New Phytol. 211, 149-158. doi: 10.1111/nph. 13892

Farquhar, G. D., von Caemmerer, S., and Berry, J. A. (1980). A biochemical model of photosynthetic $\mathrm{CO}_{2}$ assimilation in leaves of $\mathrm{C}_{3}$ species. Planta 149, 78-90. doi: $10.1007 / \mathrm{BF} 00386231$

Fu, J., and Huang, B. (2003). Effects of foliar application of nutrients on heat tolerance of creeping bentgrass. J. Plant Nutr. 26, 81-96. doi: 10.1081/pln120016498

Funk, J. L., Glenwinkel, L. A., and Sack, L. (2013). Differential allocation to photosynthetic and non-photosynthetic nitrogen fractions among native and invasive species. PLOS ONE 8:e64502. doi: 10.1371/journal.pone. 0064502

Galle, A., Florez-Sarasa, I., Thameur, A., Paepe, R., de Flexas, J., and RibasCarbo, M. (2010). Effects of drought stress and subsequent rewatering on photosynthetic and respiratory pathways in Nicotiana sylvestris wild type and the mitochondrial complex I deficient CMSII mutant. J. Exp. Bot. 61, 765-775. doi: 10.1093/jxb/erp344

Gao, Y. X., Li, Y., Yang, X. X., Li, H. J., Shen, Q. R., and Guo, S. W. (2010). Ammonium nutrition increases water absorption in rice seedlings (Oryza sativa L.) under water stress. Plant Soil 331, 193-201. doi: 10.1007/s11104-0090245-1

Garg, B. K., Kathju, S., and Burman, U. (2001). Influence of water stress on water relations, photosynthetic parameters and nitrogen metabolism of moth bean genotypes. Biol. Plant. 44, 289-292. doi: 10.1023/A:1010215812791

Giannopolitis, C. N., and Ries, S. K. (1977). Superoxide dismutases I. Occurrence in higher plants. Plant Physiol. 59, 309-314. doi: 10.1104/pp.59.2.309

Gill, S. S., Anjum, N. A., Gill, R., Mahajan, M., and Tuteja, N. (2015). "Abiotic stress tolerance and sustainable agriculture: a functional genomics perspective," in Elucidation of Abiotic Stress Signaling in Plants, Vol. 2, ed. G. K. Pandey (New York, NY: Springer), 439-472. doi: 10.1007/978-1-4939-2540-7_16

Giuliani, R., Koteyeva, N., Voznesenskaya, E., Evans, M. A., Cousins, A. B., and Edwards, G. E. (2013). Coordination of leaf photosynthesis, transpiration, and structural traits in rice and wild relatives (Genus Oryza). Plant Physiol. 162, 1632-1651. doi: 10.1104/pp.113.217497

Gojon, A., Nacry, P., and Davidian, J. C. (2009). Root uptake regulation: a central process for NPS homeostasis in plants. Curr. Opin. Plant Biol. 12, 328-338. doi: 10.1016/j.pbi.2009.04.015 
Gonzalez-Dugo, V., Durand, J. L., and Gastal, F. (2010). Water deficit and nitrogen nutrition of crops. A review. Agron. Sustain. Dev. 30, 529-544. doi: 10.1051/ agro/2009059

Gu, J., Zhou, Z., Li, Z., Chen, Y., Wang, Z., and Zhang, H. (2017). Rice (Oryza sativa L.) with reduced chlorophyll content exhibit higherphotosynthetic rate and efficiency, improved canopy light distribution, and greater yields than moderately pigmented plants. Field Crops Res. 200, 58-70. doi: 10.1016/j.fcr. 2016.10.008

Guan, X., and Gu, S. (2009). Photorespiration and photoprotection of grapevine (Vitis vinifera L. cv. Cabernet Sauvignon) under water stress. Photosynthetica 47, 437-444. doi: 10.1007/s11099-009-0067-7

Guo, S., Chen, G., Zhou, Y., and Shen, Q. (2007). Ammonium nutrition increases photosynthesis rate under water stress at early development stage of rice (Oryza sativa L.). Plant Soil 296, 115-124. doi: 10.1007/s11104-007-9302-9

Hacke, U. G., Plavcová, L., Almeidarodriguez, A., Kingjones, S., Zhou, W., and Cooke, J. E. (2010). Influence of nitrogen fertilization on xylem traits and aquaporin expression in stems of hybrid poplar. Tree Physiol. 30, 1016-1025. doi: 10.1093/treephys/tpq058

Haefele, S. M., Jabbar, S. M. A., Siopongco, J. D. L. C., Tirol-Padre, A., Amarante, S. T., Sta Cruz, P. C., et al. (2008). Nitrogen use efficiency in selected rice (Oryza sativa L.) genotypes under different water regimes and nitrogen levels. Field Crops Res. 107, 137-146. doi: 10.1016/j.fcr.2008.01.007

Han, Y. L., Song, H. X., Liao, Q., Yu, Y., Jian, S. F., Lepo, J. E., et al. (2016). Nitrogen use efficiency is mediated by vacuolar nitrate sequestration capacity in roots of Brassica napus. Plant Physiol. 170, 1684-1698. doi: 10.1014/pp.15.01377

Hassan, I. A., Basahi, J. M., and Kadi, M. W. (2012). Physiological and biochemical impairment in bean plants due to supplementary ultraviolet radiation and water stress: possible protective roles of secondary metabolites. Aust. J. Basic Appl. Sci. 6, 552-563.

Havir, E. A., and Mchale, N. A. (1987). Biochemical and development characterization of multiples forms of catalase in tobacco-leaves. Plant Physiol. 84, 450-455. doi: 10.1104/pp.84.2.450

Hoai, N. T. T., Shim, I. S., Kobayashi, K., and Kenji, U. (2003). Accumulation of some nitrogen compounds in response to salt stress and their relationships with salt tolerance in rice (Oryza sativa L.) seedlings. Plant Growth Regul. 41, 159-164. doi: 10.1023/A:1027305522741

Hodges, D. M., DeLong, J. M., Forney, C. F., and Prange, R. K. (1999). Improving the thiobarbituric acid-reactive-substances assay for estimating lipid peroxidation in plant tissues containing anthocyanin and other interfering compounds. Planta 207, 604-611. doi: 10.1007/s004250050524

Igarashi, D., Tsuchida, H., Miyao, M., and Ohsumi, C. (2006). Glutamate:glyoxylate aminotransferase modulates amino acid content during photorespiration. Plant Physiol. 142, 901-910. doi: 10.1104/pp.085514

Jangam, A. P., and Raghuram, N. (2015). "Nitrogen and stress," in Elucidation of Abiotic Stress Signaling in Plants, Vol. 2, ed. G. K. Pandey (New York, NY: Springer), 323-339. doi: 10.1007/978-1-4939-2540-7_12

Karasov, T., Chae, E., Herman, J., and Bergelson, J. (2017). Mechanisms to mitigate the trade-off between growth and defense. Plant Cell 29, 666-680. doi: 10.1105/ tpc. 16.00931

Kumar, P. A., Parry, M. A. J., Mitchell, R. A. C., Ahmad, A., and Abrol, Y. P. (2006). "Photosynthesis and nitrogen-use efficiency," in Photosynthetic Nitrogen Assimilation and Associated Carbon and Respiratory Metabolism, eds C. H. Foyer and G. Noctor (Dordrecht: Springer), 23-34. doi: 10.1007/0-30648138-3_2

Lassaletta, L., Billen, G., Grizzetti, B., Anglade, J., and Garnier, J. (2014). 50 year trends in nitrogen use efficiency of world cropping systems: the relationship between yield and nitrogen input to cropland. Environ. Res. Lett. 9:105011. doi: 10.1088/1748-9326/9/10/105011

Lawlor, D. W. (2002). Carbon and nitrogen assimilation in relation to yield: mechanisms are the key to understanding production systems. J. Exp. Bot. 53, 773-787. doi: 10.1093/jexbot/53.370.773

Li, Y., Gao, Y. X., Xu, X. M., Shen, Q. R., and Guo, S. W. (2009). Light-saturated photosynthetic rate in high-nitrogen rice (Oryza sativa L.) leaves is related to chloroplastic $\mathrm{CO}_{2}$ concentration. J. Exp. Bot. 60, 2351-2360. doi: 10.1093/jxb/ erp 127

Loulakakis, C. A., and Roubelakis-Angelakis, K. (1990). Intracellular localization and properties of NADH-glutamate dehydrogenase form Vitis vinifera L.: purification and characterization of the major leaf isoenzyme. J. Exp. Bot. 41, 1223-1230. doi: 10.1093/jxb/41.10.1223

Makino, A., Nakano, H., Mae, T., Shimada, T., and Yamamoto, N. (2000). Photosynthesis, plant growth and $\mathrm{N}$ allocation in transgenic rice plants with decreased Rubisco under $\mathrm{CO}_{2}$ enrichment. J. Exp. Bot. 51, 383-389. doi: 10. 1093/jexbot/51.suppl_1.383

Makino, A., Sakuma, H., Sudo, E., and Mae, T. (2003). Differences between maize and rice in $\mathrm{N}$-use efficiency for photosynthesis and protein allocation. Plant Cell Physiol. 44, 952-956. doi: 10.1093/pcp/pcg113

Manzoni, S., Vico, G., Palmroth, S., Porporato, A., and Katul, G. (2013). Optimization of stomatal conductance for maximum carbon gain under dynamic soil moisture. Adv. Water Resour. 62, 90-105. doi: 10.1016/j.advwatres. 2013.09.020

Masclaux-Daubresse, C., Reisdorf-Cren, M., Pageau, K., Lelandais, M., Grandjean, O., Kronenberger, J., et al. (2006). Glutamine synthetaseglutamate synthase pathway and glutamate dehydrogenase play distinct roles in the sink-source nitrogen cycle in tobacco. Plant Physiol. 140, 444-456. doi: 10.1104/pp.105.071910

Miflin, B. J., and Habash, D. Z. (2002). The role of glutamine synthetase and glutamate dehydrogenase in nitrogen assimilation and possibilities for improvement in the nitrogen utilization of crops. J. Exp. Bot. 53, 979-987. doi: $10.1093 /$ jexbot/53.370.979

Misra, A. N., Misra, M., and Singh, R. (2012). "Chlorophyll fluorescence in plant biology,” in Biophysics, ed. M. N. Misra (Rijeka: In Tech), 171-192. doi: 10.5772/ 35111

Nagy, Z., Németh, E., Guóth, A., Bona, L., Wodala, B., and Pécsváradi, A. (2013). Metabolic indicators of drought stress tolerance in wheat: glutamine synthetase isoenzymes and Rubisco. Plant Physiol. Biochem. 67, 48-54. doi: 10.1016/j. plaphy.2013.03.001

Niinemets, Ü., Díaz-Espejo, A., Flexas, J., Galmés, J., and Warren, C. R. (2009). Role of mesophyll diffusion conductance in constraining potential photosynthetic productivity in the field. J. Exp. Bot. 60, 2249-2270. doi: 10.1016/0732-8893(90) 90102-2

Nunes-Nesi, A., Fernie, A. R., and Stitt, M. (2010). Metabolic and signaling aspects underpinning the regulation of plant carbon nitrogen interactions. Mol. Plant 3, 973-996. doi: 10.1093/mp/ssq049

Otoo, E., Ishii, R., and Kumura, A. (1989). Interaction of nitrogen supply and soil water stress on photosynthesis and transpiration in rice. Jpn. J. Crop Sci. 58, 424-429. doi: 10.1626/jcs.58.424

Parry, M. A. J., Andralojc, P. J., Scales, J. C., Salvucci, M. E., Carmo-Silva, A. E., Alonso, H., et al. (2013). Rubisco activity and regulation as targets for crop improvement. J. Exp. Bot. 64, 717-730. doi: 10.1093/jxb/ers336

Peterhansel, C., Horst, I., Niessen, M., Blume, C., Kebeish, R., Kürkcüoglu, S., et al. (2010). Photorespiration. Arabidopsis Book 8:e0130. doi: 10.1199/tab.0130

Peterhansel, C., and Maurino, V. G. (2011). Photorespiration redesigned. Plant Physiol. 155, 49-55. doi: 10.1104/pp.110.165019

Pinheiro, C., and Chaves, M. M. (2011). Photosynthesis and drought: can we make metabolic connections from available data? J. Exp. Bot. 62, 869-882. doi: $10.1093 /$ jxb/erq340

Ramalho, J. C., Campos, P. S., Teixeira, M., and Nunes, M. A. (1998). Nitrogen dependent changes in antioxidant system and in fatty acid composition of chloroplast membranes from Coffea arabica L. plants submitted to high irradiance. Plant Sci. 135, 115-124. doi: 10.1016/S0168-9452(98)00073-9

Rivero, R. M., Shulaev, V., and Blumwald, E. (2009). Cytokinin-dependent photorespiration and the protection of photosynthesis during water deficit. Plant Physiol. 150, 1530-1540. doi: 10.1104/pp.109.139378

Sedmak, J. J., and Grossberg, S. E. (1977). A rapid, sensitive, and versatile assay for protein using Coomassie brilliant blue G250. Anal. Biochem. 79, 544-552. doi: 10.1016/0003-2697(77)90428-6

Sharkey, T. D., Bernacchi, C. J., Farquhar, G. D., and Singsaas, E. L. (2007). Fitting photosynthetic carbon dioxide response curves for $\mathrm{C}_{3}$ leaves. Plant Cell Environ. 30, 1035-1040. doi: 10.1111/j.1365-3040.2007.01710.x

Silva, E. N., Silveira, J. A. G., Ribeiro, R. V., and Vieira, S. A. (2015). Photoprotective function of energy dissipation by thermal processes and photorespiratory mechanisms in Jatropha curcas plants during different intensities of drought and after recovery. Environ. Exp. Bot. 110, 36-45. doi: 10.1016/j.envexpbot. 2014.09.008 
Singh, K. K., and Ghosh, S. (2013). Regulation of glutamine synthetase isoforms in two differentially drought-tolerant rice (Oryza sativa L.) cultivars under water deficit conditions. Plant Cell Rep. 32, 183-193. doi: 10.1007/s00299-012-1353-6

Singh, M., Singh, V. P., and Prasad, S. M. (2016). Responses of photosynthesis, nitrogen and proline metabolism to salinity stress in Solanum lycopersicum under different levels of nitrogen supplementation. Plant Physiol. Biochem. 109, 72-83. doi: 10.1016/j.plaphy.2016.08.021

Singh, N. B., Singh, D., and Singh, A. (2015). Biological seed proming mitigates the effects of water stress in sunflower seedlings. Physiol. Mol. Biol. Plants 21, 207-214. doi: 10.1007/s12298-015-0291-5

Singh, R. P., and Srivastava, H. S. (1986). Increase in glutamate synthase (NADH) activity in maize seedlings in response to nitrate and ammonium nitrogen. Physiol. Plant. 66, 413-416. doi: 10.1111/j.1399-3054.1986.tb05944.x

Sun, S. W., Lin, Y. C., Weng, Y. M., and Chen, M. J. (2006). Efficiency improvements on ninhydrin method foramino acid quantification. J. Food Comp. Anal. 19, 112-117. doi: 10.1016/j.jfca.2005.04.006

Sunil, B., Talla, S. K., Aswani, V., and Raghavendra, A. S. (2013). Optimization of photosynthesis by multiple metabolic pathways involving interorganelle interactions: resource sharing and ROS maintenance as the bases. Photosynth. Res. 117, 61-71. doi: 10.1007/s11120-013-9889-z

Szabados, L. L., and Savouré, A. (2010). Proline: a multifunctional amino acid. Trends Plant Sci. 15, 89-97. doi: 10.1016/j.tplants.2009.11.009

Tabuchi, M., Abiko, T., and Yamaya, T. (2007). Assimilation of ammonium ions and reutilization of nitrogen in rice (Oryza sativa L.). J. Exp. Bot. 58, 2319-2327. doi: 10.1093/jxb/erm016

Thomsen, H. C., Eriksson, D., Moller, I. S., and Schjoerring, J. K. (2014). Cytosolic glutamine synthetase: a target for improvement of crop nitrogen use efficiency? Trends Plant Sci. 19, 656-663. doi: 10.1016/j.tplants.2014.06.002

Tosens, T., Niinemets, Ü., Vislap, V., Eichelmann, H., and Díez, P. C. (2012). Developmental changes in mesophyll diffusion conductance and photosynthetic capacity under different light and water availabilities in Populus tremula: how structure constrains function. Plant Cell Environ. 35, 839-856. doi: 10.1111/j.1365-3040.2011.02457.x

Tran, T. T., and Yamauchi, A. (2014). Nitrogen application enhanced the expression of developmental plasticity of root systems triggered by mild drought stress in rice. Plant Soil 378, 139-152. doi: 10.1007/s11104-013-2013-5

von Caemmerer, S., and Farquhar, G. D. (1981). Some relationships between the biochemistry of photosynthesis and the gas exchange of leaves. Planta 153, 376-387. doi: 10.1007/BF00384257

Walch-Liu, P., Filleur, S., Gan, Y., and Forde, B. G. (2005). Signaling mechanisms integrating root and shoot response to changes in the nitrogen supply. Photosynth. Res. 83, 239-250. doi: 10.1007/s11120-004-2080-9

Wang, Z., Wang, Z., Zhang, W., Beebout, S. S., Zhang, H., Liu, L., et al. (2016). Grain yield, water and nitrogen use efficiencies of rice as influenced by irrigation regimes and their interaction with nitrogen rates. Field Crops Res. 193, 54-69. doi: 10.1016/j.fcr.2016.03.006

Wellburn, A. R., and Lichtenthaler, H. K. (1984). "Formulae and program to determine total carotenoids and chlorophylls a and b of leaf extracts in different solvents," in Advances in Photosynthesis Research, ed. C. Sybesma (Dordrecht: Springer), 9-12. doi: 10.1007/978-94-017-6368-4_3

Wu, Z. M., Zhang, X., Wang, J. L., and Wan, J. M. (2014). Leaf chloroplast ultrastructure and photosynthetic properties of a chlorophyll-deficient mutant of rice. Photosynthetica 52, 217-222. doi: 10.1007/s11099-014-0025-X

Xiong, D., Yu, T., Liu, X., Li, Y., Peng, S., and Huang, J. (2015). Heterogeneity of photosynthesis within leaves is associated with alteration of leaf structural features and leaf $\mathrm{N}$ content per leaf area in rice. Funct. Plant Biol. 42, 687-696. doi: 10.1071/FP15057
Xu, G., Wang, H., Zhai, Z., Sun, M., and Li, Y. (2015). Effect of water and nitrogen coupling on root morphology and physiology, yield and nutrition utilization for rice. Trans. Chin. Soc. Agric. Eng. 31, 132-141. doi: 10.11975/j.issn.1002-6819. 2015.10.018

Xu, H., Lu, Y., Xie, Z., and Song, F. (2014). Changes in nitrogen metabolism and antioxidant enzyme activities of maize tassel in black soils region of northeast China. Front. Plant Sci. 5:515. doi: 10.3389/fpls.2014. 00515

Xu, Z. Z., and Zhou, G. S. (2005). Effects of water stress on photosynthesis and nitrogen metabolism in vegetative and reproductive shoots of Leymus chinensis. Photosynthetica 43, 29-35. doi: 10.1007/s11099-005-0035-9

Xu, Z. Z., and Zhou, G. S. (2006). Nitrogen metabolism and photosynthesis in Leymus chinensis in response to long-term soil drought. J. Plant Growth Regul. 25, 252-266. doi: 10.1007/s00344-006-0043-4

Yang, Y. J., Cheng, L. M., and Liu, Z. H. (2007). Rapid effect of cadmium on lignin biosynthesis in soybean roots. Plant Sci. 172, 632-639. doi: 10.1016/j.plantsci. 2006.11.018

Yi, X. P., Zhang, Y. L., Yao, H. S., Zhang, X. J., Luo, H. H., Gou, L., et al. (2014). Alternative electron sinks are crucial for conferring photoprotection in field grown cotton under water deficit during flowering and boll setting stages. Funct. Plant Biol. 41, 737-747. doi: 10.1071/FP13269

Yokoyama, S., and Hiramatsu, J. I. (2003). A modified ninhydrin reagent using ascorbic acid instead of potassium cyanide. J. Biosci. Bioeng. 95, 204-205. doi: 10.1016/S1389-1723(03)80131-7

Zanini, E. (2001). Indophenol blue colorimetric method for measuring cation exchange capacity in sandy soils. Commun. Soil Sci. Plant Anal. 32, 2519-2530. doi: $10.1081 /$ CSS- 120000388

Zelitch, I. (1990). Further studies on $\mathrm{O}_{2}$-resistant photosynthesis and photorespiration in a tobacco mutant with enhanced catalase activity. Plant Physiol. 92, 352-357. doi: 10.1104/pp.92.2.352

Zhang, C., Peng, S., Peng, X., Chavez, A. Q., and Bennett, J. (1997). Response of glutamine synthetase isoforms to nitrogen sources in rice (Oryza sativa L.) roots. Plant Sci. 125, 163-170. doi: 10.1016/S0168-9452(97) 00075-7

Zhang, C., Zhan, D. X., Luo, H. H., Zhang, Y. L., and Zhang, W. F. (2016). Photorespiration and photoinhibition in the bracts of cotton under water stress. Photosynthetica 54, 12-18. doi: 10.1007/s11099-0150139-9

Zhu, X. G., Long, A. P., and Ort, D. R. (2010). Improving photosynthetic efficiency for greater yield. Annu. Rev. Plant Biol. 61, 235-261. doi: 10.1146/annurevarplant-042809-112206

Conflict of Interest Statement: The authors declare that the research was conducted in the absence of any commercial or financial relationships that could be construed as a potential conflict of interest.

The reviewer JJR and handling Editor declared their shared affiliation, and the handling Editor states that the process met the standards of a fair and objective review.

Copyright (C) 2017 Zhong, Cao, Hu, Zhu, Zhang, Huang and Jin. This is an openaccess article distributed under the terms of the Creative Commons Attribution License (CC BY). The use, distribution or reproduction in other forums is permitted, provided the original author(s) or licensor are credited and that the original publication in this journal is cited, in accordance with accepted academic practice. No use, distribution or reproduction is permitted which does not comply with these terms. 